\title{
Human Gut Faecalibacterium prausnitzii Deploys a Highly Efficient Conserved System To Cross-Feed on $\boldsymbol{\beta}$-Mannan- Derived Oligosaccharides
}

\author{
Lars J. Lindstad, a Galiana Lo, ${ }^{b}$ (D) Shaun Leivers, ${ }^{a}$ Zijia Lu, ${ }^{c}$ Leszek Michalak, ${ }^{a}$ (D) Gabriel V. Pereira, ${ }^{d}$ \\ Åsmund K. Røhr, ${ }^{\text {a }}$ (DEric C. Martens, d (D) Lauren S. McKee, c (D) Petra Louis, ${ }^{b}$ Sylvia H. Duncan, b \\ Bjørge Westereng, ${ }^{\text {a Phillip B. Pope, }}{ }^{\mathrm{a}, \mathrm{e}}$ (D) Sabina Leanti La Rosa ${ }^{\mathrm{a}, \mathrm{e}}$ \\ aFaculty of Chemistry, Biotechnology and Food Science, Norwegian University of Life Sciences, Aas, Norway \\ bGut Health Group, Rowett Institute, University of Aberdeen, Aberdeen, Scotland, United Kingdom \\ cDivision of Glycoscience, Department of Chemistry, KTH Royal Institute of Technology, AlbaNova University Centre, Stockholm, Sweden \\ dDepartment of Microbiology and Immunology, University of Michigan Medical School, Ann Arbor, Michigan, USA \\ eFaculty of Biosciences, Norwegian University of Life Sciences, Aas, Norway
}

ABSTRACT $\beta$-Mannans are hemicelluloses that are abundant in modern diets as components in seed endosperms and common additives in processed food. Currently, the collective understanding of $\beta$-mannan saccharification in the human colon is limited to a few keystone species, which presumably liberate low-molecularweight mannooligosaccharide fragments that become directly available to the surrounding microbial community. Here, we show that a dominant butyrate producer in the human gut, Faecalibacterium prausnitzii, is able to acquire and degrade various $\beta$-mannooligosaccharides ( $\beta$-MOS), which are derived by the primary mannanolytic activity of neighboring gut microbiota. Detailed biochemical analyses of selected protein components from their two $\beta$-MOS utilization loci ( $F$. prausnitzii $\beta$-MOS utilization loci [FpMULs]) supported a concerted model whereby the imported $\beta$-MOS are stepwise disassembled intracellularly by highly adapted enzymes. Coculturing experiments of $F$. prausnitzii with the primary degraders Bacteroides ovatus and Roseburia intestinalis on polymeric $\beta$-mannan resulted in syntrophic growth, thus confirming the high efficiency of the FpMULs' uptake system. Genomic comparison with human $F$. prausnitzii strains and analyses of 2,441 public human metagenomes revealed that FpMULs are highly conserved and distributed worldwide. Together, our results provide a significant advance in the knowledge of $\beta$-mannan metabolism and the degree to which its degradation is mediated by cross-feeding interactions between prominent beneficial microbes in the human gut.

IMPORTANCE Commensal butyrate-producing bacteria belonging to the Firmicutes phylum are abundant in the human gut and are crucial for maintaining health. Currently, insight is lacking into how they target otherwise indigestible dietary fibers and into the trophic interactions they establish with other glycan degraders in the competitive gut environment. By combining cultivation, genomic, and detailed biochemical analyses, this work reveals the mechanism enabling F. prausnitzii, as a model Ruminococcaceae within Firmicutes, to cross-feed and access $\beta$-mannan-derived oligosaccharides released in the gut ecosystem by the action of primary degraders. A comprehensive survey of human gut metagenomes shows that FpMULs are ubiquitous in human populations globally, highlighting the importance of microbial metabolism of $\beta$-mannans/ $\beta$-MOS as a common dietary component. Our findings provide a mechanistic understanding of the $\beta$-MOS utilization capability by $F$. prausnitzii that may be exploited to select dietary formulations specifically boosting this beneficial symbiont, and thus butyrate production, in the gut.
Citation Lindstad L, Lo G, Leivers S, Lu Z, Michalak L, Pereira GV, Røhr ÅK, Martens EC, McKee LS, Louis P, Duncan SH, Westereng B Pope PB, La Rosa SL. 2021. Human gut Faecalibacterium prausnitzii deploys a highly efficient conserved system to cross-feed on $\beta$-mannan-derived oligosaccharides. mBio 12 e03628-20. https://doi.org/10.1128/mBio .03628-20.

Editor Maria Gloria Dominguez Bello, Rutgers, The State University of New Jersey Copyright $\odot 2021$ Lindstad et al. This is an open-access article distributed under the terms of the Creative Commons Attribution 4.0 International license.

Address correspondence to Sabina Leanti La Rosa, sabina.leantilarosa@nmbu.no.

Received 22 December 2020

Accepted 26 April 2021

Published 1 June 2021 
KEYWORDS $\beta$-mannan, $\beta$-mannoligosaccharides, butyrate producer, short-chain fatty acids, carbohydrate active enzymes, human gut microbiota, cross-feeding interactions

T he human distal gut supports a densely populated microbial community that extends the metabolic capabilities lacking in the host genome (1). In particular, recalcitrant glycans that are resistant to human digestive enzymes are broken down by the colonic microbiota to monosaccharides and further fermented into host-absorbable short-chain fatty acids (SCFAs). Microbial-borne SCFAs serve critical functions both as energy sources and regulators of inflammation, cell proliferation, and apoptosis (2). Therefore, catabolism of complex dietary carbohydrates reaching the distal part of the gastrointestinal tract has a central role in shaping the structure and metabolic output of the human gut microbiota and, in turn, host health status (3).

Members of the Gram-positive Firmicutes and the Gram-negative Bacteroidetes phyla constitute the majority of the bacteria found in this ecosystem (4), individual species of which have evolved different strategies to harvest energy from the available dietary glycans (5). Within the Bacteroidetes, Bacteroides spp. have been extensively investigated with respect to carbohydrate degradation, and they are considered generalists, displaying broad plasticity for glycan utilization (5). Bacteroides spp. are particularly notable for dedicating large proportions of their genome to carbohydrate utilization, organizing genes coding for functionally related carbohydrate active enzymes (CAZymes) and transport and regulatory proteins into polysaccharide utilization loci (PULs) (6). Despite variations in the polysaccharides they target, the key feature of a PUL is the presence of one or more TonB-dependent receptor (SusC homolog) and a contiguous substrate-binding lipoprotein (SusD homolog). Compared with Bacteroides, Firmicutes encode a lower proportional number of CAZymes and are thought to be nutritionally specialized for selected glycans $(1,5)$. Recently, species within the Firmicutes phylum have been shown to organize cohorts of genes encoding glycan utilization systems into loci and being primary degraders of common dietary carbohydrates (7-9). Firmicutes typically utilize glycan-specific ATP-binding cassette (ABC) transporters, which mediate high-affinity capture of oligosaccharides via their extracellular solute-binding proteins (SBPs) (5).

Faecalibacterium prausnitzii, a member of the Ruminococcaceae family within the Firmicutes phylum, is one of the three most abundant species detected in the human gut microbiota and one of the main sources of butyrate in the colon (10). A growing body of evidence recognizes the crucial role played by $F$. prausnitzii populations in maintaining local and systemic host health, as they are often found to be less abundant in individuals affected by colorectal cancer (11) and certain forms of inflammatory disorders, including alternating-type irritable bowel syndrome (IBS), inflammatory bowel diseases, celiac disease, obesity and type 2 diabetes, appendicitis, and chronic diarrhea $(12,13)$. In addition, studies in mouse models have demonstrated that both cell and supernatant fractions of $F$. prausnitzii reduce the severity of acute, chronic, and low-level chemically induced inflammations $(14,15)$. F. prausnitzii also contributes to colonic epithelial homeostasis by stimulating the production of mucin O-glycans and by maintaining appropriate proportions of different cell types of the secretory lineage (16). Collectively, these aforementioned properties make F. prausnitzii a potential novel health-promoting probiotic (17), and interventions aimed at increasing the representation of these butyrate-producing bacteria may be used to confer protection against several intestinal disorders.

A common component of the human diet are $\beta$-mannans. These complex plant glycans are found in high concentrations as naturally occurring dietary fibers in certain nuts, beans, legume seeds, tomato seeds, coconut, and coffee beans (18). In addition, mannan hydrocolloids, including guar gum and carob galactomannan (CGM) as well as konjac glucomannan (KGM), are widely used in the food industry to improve the rheological properties of processed products (19). The constant exposure of the gut bacterial community to dietary mannans is consistent with the finding that $\beta$-mannan 
metabolism is one of the core pathways in the human gut microbiota (20). Structurally, $\beta$-mannans display source-related diversity with respect to the presence of $\beta-1,4-$ linked mannosyl and glycosyl residues, $\alpha$-1,6-linked galactosyl groups and acetyl decorations at positions $0-2,0-3$, and/or O-6 (18). PULs degrading homopolymeric mannan and galactomannan have been described in the glycan generalists Bacteroides fragilis and Bacteroides ovatus, respectively $(21,22)$. We recently reported the characterization of a novel $\beta$-mannan utilization locus conferring Roseburia intestinalis, a model for the clostridial cluster XIVa (Lachnospiraceae) Firmicutes, with the ability to ferment this fiber through to butyrate via a selfish mechanism (7). $\beta$-Mannan degradation was proven to be initiated by an endo-acting multimodular GH26 enzyme localized on the cell surface; the resulting oligosaccharides are imported intracellularly through a highly specific $A B C$ transporter, and completely depolymerized to their component monosaccharides by an enzymatic cocktail containing carbohydrate esterases, $\beta$-glucosidases, and phosphorylases (7).

Although F. prausnitzii has been described as an efficient degrader of host-derived and plant glycans (23), the ability of this important butyrate-producing microbe to utilize dietary $\beta$-mannans has received little attention. In a previous study, we reported that wood-derived acetylated galactoglucomannan stimulates the proliferation of $F$. prausnitzii populations in a $\mathrm{pH}$-controlled batch culture fermentation system inoculated with healthy adult human feces (24). However, the molecular mechanism underlining $\beta$-mannan utilization by F. prausnitzii in the human gut has not been explored thus far.

In this study, we describe and biochemically characterize components of two loci that mediate acquisition and catabolism of $\beta$-mannooligosaccharides ( $\beta$-MOS) by the human gut isolate $F$. prausnitzii SL3/3. Together, these data allowed us to outline a pathway for dietary $\beta$-MOS deconstruction and saccharification to monosaccharides through cross-feeding with Bacteroides and Roseburia species, which contributes to the ecology of $\beta$-mannan utilization in the gut ecosystem. Remarkably, we show that the binding proteins that confer $\beta$-MOS capture in F. prausnitzii targeted ligands with stronger affinity than that of Bacteroides species, thus providing $F$. prausnitzii with the ability to cross-feed on the $\beta$-MOS available in the environment with high efficiency.

\section{RESULTS}

F. prausnitzii possess two loci for utilization of $\boldsymbol{\beta}$-mannan breakdown products. Based on the similarity with the components from the previously characterized $\beta$-mannan utilization system in $R$. intestinalis (7), genes encoding enzymatic activities required to catabolize mannans were identified within two putative mannan utilization loci (MULs) in F. prausnitzii SL3/3 (Fig. 1a). The large MUL from F. prausnitzii (FpMULL) consists of 14 genes encoding nine enzymes, the components of an $A B C$ transporter, a predicted Lacl-type transcriptional regulator (TR), and a hypothetical protein (Fig. 1a). The enzymes encoded by FpMULL include an $\alpha$-galactosidase belonging to the glycoside hydrolase $(\mathrm{GH})$ family 36 (FpGH36), two carbohydrate esterases (CEs [FpCE2 and FpCE17]), a GH113 (FpGH113), one epimerase (FpMep), a $\beta$-1,4-mannooligosaccharide phosphorylase (FpGH130_2), a mannosylglucose phosphorylase (FpGH130_1), a phosphomutase ( $F p P m m)$ and a $\mathrm{GH} 1$ isomerase $(F p G H 1)$. In addition, genes encoding two predicted $\mathrm{GH} 3 \beta$-glucosidases ( $F p G H 3 A$ and $F p G H 3 B$ ) were identified. These two genes are located in a different locus in the genome, hereafter referred to as FpMULS, and are likely to be involved in (galacto)glucomannan turnover. Based on known activities within $\mathrm{GH}$ families, the $\beta$-1,4-mannan backbone is predicted to be hydrolyzed by extracellular GH26, GH5, and/or GH134 enzymes (see www.cazy.org). However, no gene coding for such an enzyme was identified in the genome of $F$. prausnitzii SL3/3. In addition, endo- $\beta$-1,4-mannanase activity was originally reported for two $\mathrm{GH} 113$ enzymes (see www.cazy.org), although we demonstrated that a GH113 within the mannan utilization locus of $R$. intestinalis is a reducing end mannose-releasing exo-oligomannosidase. A gene encoding a GH113 was detected in the FpMULL (Fig. 1a). 


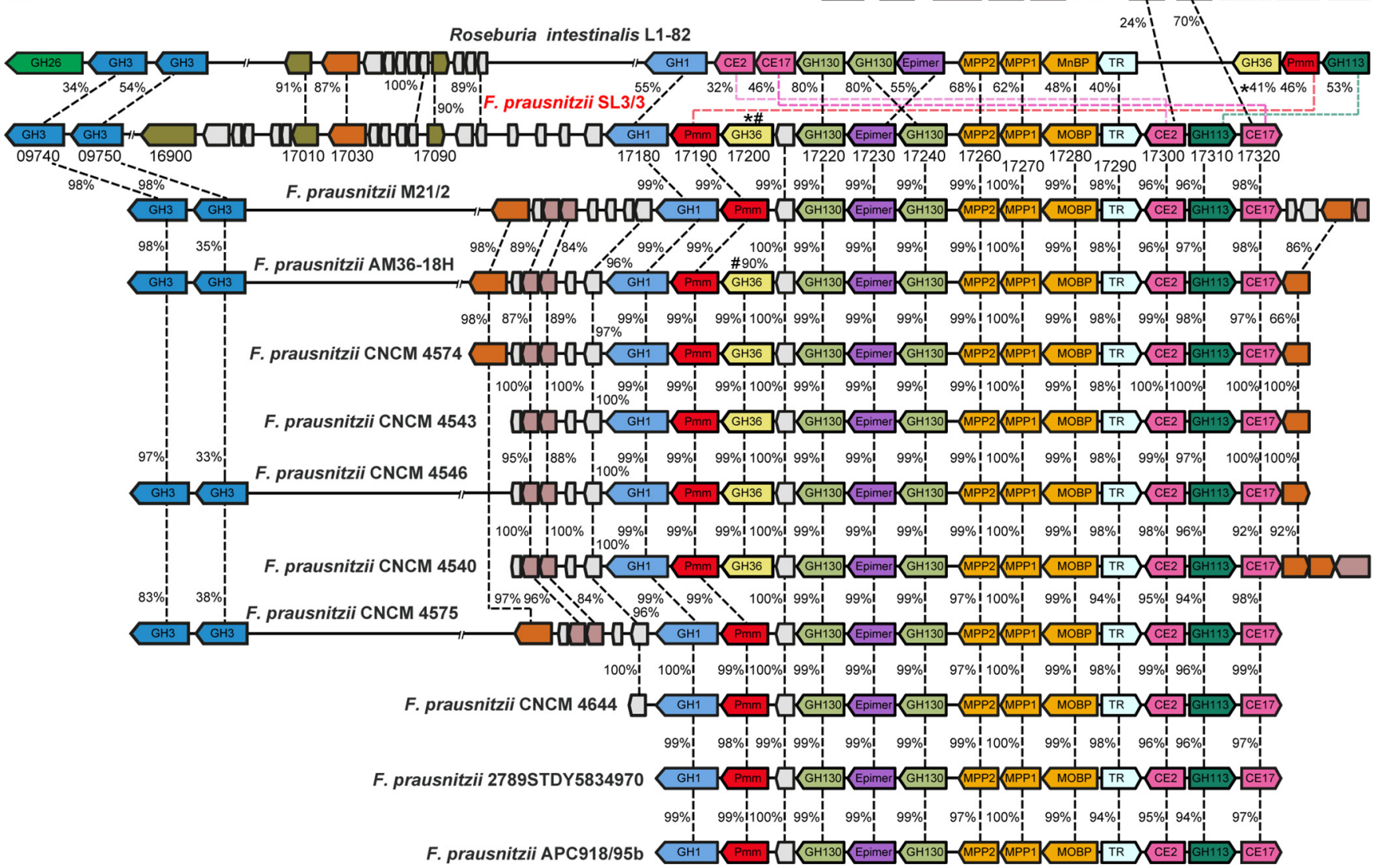

F. prausnitzii APC918/95b GH1 Pmm

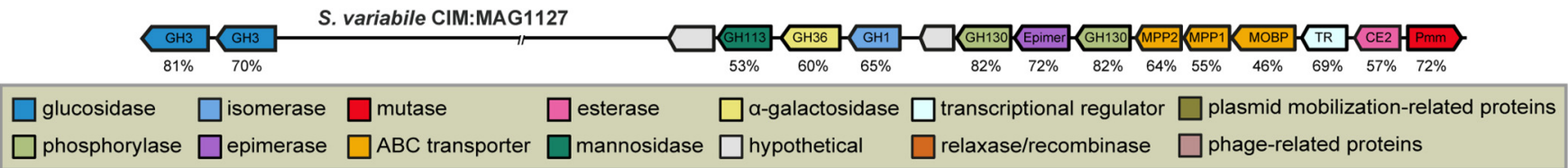

b Heatmap color key

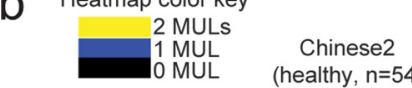
Chinese1 CRC, $\mathrm{n}=74$ )

Chinese1

(healthy, $n=185$;

diabetic, $n=160$ )

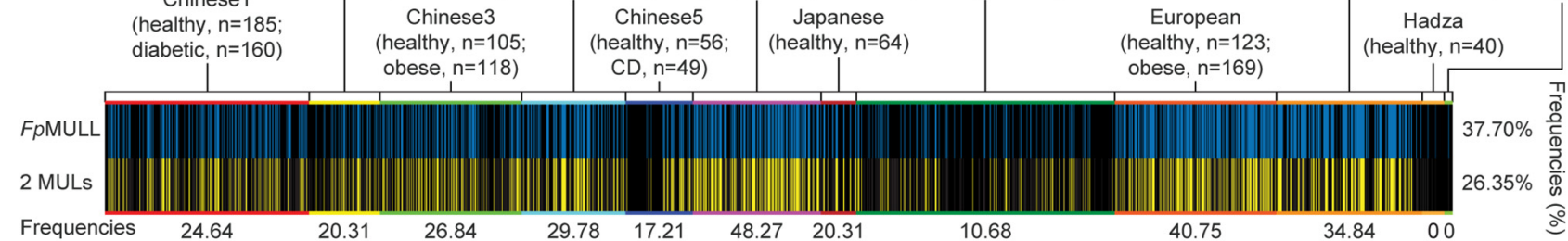

Chinese4 Chinese6 (diabetic, $n=188) \quad(R A, n=232)$
European

(healthy, $\mathrm{n}=85$;
UC, $\mathrm{n}=27 ; C D, \mathrm{n}=12$ ) (healthy, $n=468$ )

2 MULs (\%)

FIG $1 \mathrm{~F}$. prausnitzii loci involved in $\beta$-mannooligosaccharide degradation and metagenomic analysis of the occurrence of the loci in 2,441 human metagenomes. (a) Large and small $\beta$-mannooligosaccharide utilization loci (MULL and MULS, respectively) genomic structure in F. prausnitzii SL3/3 and across other publicly available $F$. prausnitzii genomes. In $F$. prausnitzii SL3/3, locus tag numbers FPR_XXXXX are abbreviated with the last numbers after the low line ( (). FpMULS corresponds to the genes 09740 to 09750, while FpMULL includes the genes 17180 to 17320 . Numbers between each gene indicate the amino acid identity (\%) of the encoded protein. Numbers below S. variabile CIM:MAG1127 genes indicate the amino acid identity (\%) of the encoded proteins shared with the same protein in F. prausnitzii SL3/3. (b) Prevalence of FpMULL as well as both FpMULL and FpMULS (two MULs) in human metagenomes. Each line denotes the presence (blue or yellow) or absence (black) of the FpMULL/MULs related in a single human gut metagenomic sample. The numbers below the bottom row represent the frequency of FpMULs that each cohort possesses. The frequency of FpMULL/MULs incidence across all 2,441 individuals is shown on the right. CRC, colorectal cancer; RA, rheumatoid arthritis; CD, Crohn's disease; UC, ulcerative colitis.

Based on the results of a genomic context analysis and in silico prediction of a signal peptide, $\mathrm{FpGH} 113$ would function as an intracellular mannanase or mannosidase; thus, its enzymatic function could not be assigned before an in-depth biochemical characterization (see later results for $F p G H 113$ ). 
a

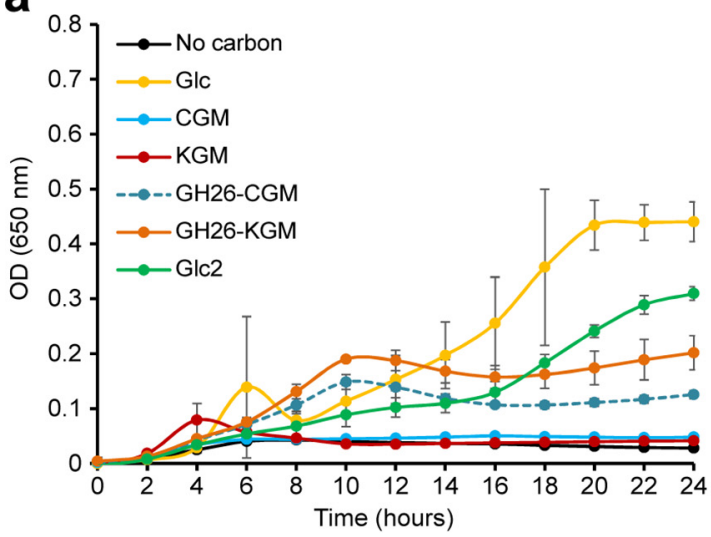

b

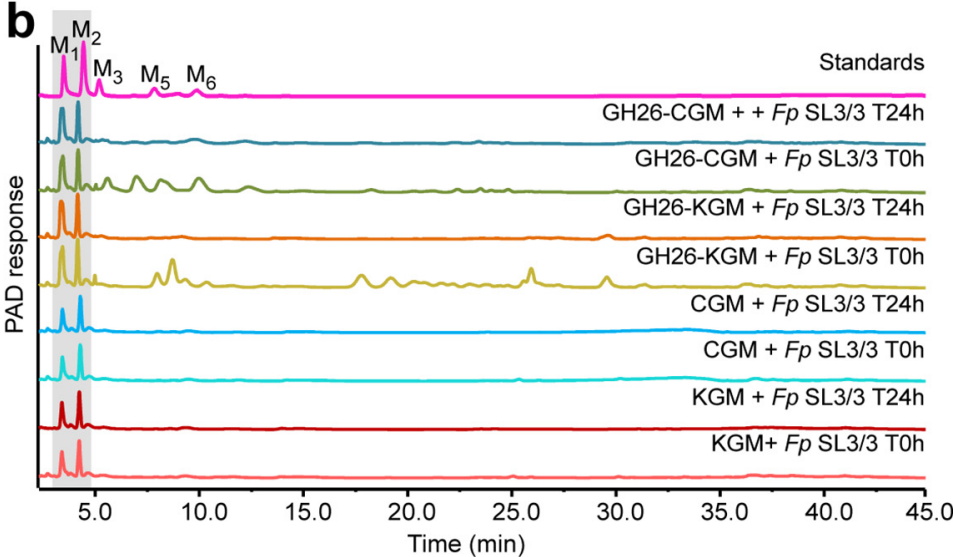

FIG 2 Growth profile and carbohydrate consumption of $F$. prausnitzii SL3/3. (a) Cells were grown on M2 medium supplemented with $0.2 \%$ (wt/vol) polysaccharide (CGM, carob galactomannan; KGM, konjac glucomannan), oligosaccharides (GH26-CGM, RiGH26-pretreated carob galactomannan; GH26KGM, RiGH26-pretreated konjac glucomannan), cellobiose (Glc2), and glucose (Glc) as the sole carbon source. Data are averages \pm standard deviations (error bars) of three biological replicates. (b) Analysis of the growth medium used in the experiment described in panel a by HPAEC-PAD. Traces show mannose, mannooligosaccharides, and polysaccharides detected in the supernatant before (TOh) and after fermentation (T24h) with $F$. prausnitzii. Samples were chromatographed with the following external standards: $M_{1}$, mannose; $M_{2}$, mannobiose; $M_{3}$, mannotriose; $M_{5}$, mannopentaose; $M_{6}$, mannohexaose. The data displayed are examples from three biological replicates.

Genomic comparisons showed that homologous systems to the FpMULL and FpMULS occur in other sequenced Faecalibacterium members with high percentages of identity (Fig. 1a). Comparison of the gene organization and protein sequence also revealed various levels of rearrangements and moderate protein homology with the two $\beta$-mannan utilization loci from $R$. intestinalis. Examination of the regions flanking the FpMULL of $F$. prausnitzii SL3/3 showed the presence of genes encoding plasmid mobilization-related proteins, including a cell invasion protein, a relaxase MobA/VirD2, and a DNA ligase (Fig. 1a). Interestingly, R. intestinalis L1-82 genome harbors a similar region, including genes coding for the same plasmid-related components, suggesting that the origin of FpMULL could be the result of horizontal transfer through bacterial conjugation within colonic microbes. Further comparisons revealed that the genes located upstream and downstream of the FpMULL of F. prausnitzii M21/2 and six other sequenced $F$. prausnitzii strains code for an incomplete prophage, including one or two relaxases and an integrase (Fig. 1a). On the basis of these results, we hypothesize that phage-related horizontal gene transfer was an alternative mechanism for the acquisition of this cluster at the same point in the evolutionary history of these strains. Orthologues of both MULL and MULS, with some rearrangements, were identified in Subdoligranulum variabile CIM:MAG 1127, suggesting that mannan utilization could be a metabolic feature shared with other Ruminococcaceae members.

To further understand the distribution of the two MULs within human-associated $F$. prausnitzii strains, we surveyed the publicly available metagenome data from a total of 2,441 individuals from regions with distinct geography (North America, Europe, China, and Japan) and dietary patterns (Fig. 1b). Overall, $26.35 \%$ of the subjects harbor the two FpMULs identified in this study, while $37.70 \%$ carry the FpMULL, irrespective of the nationality or health state. When examined for frequency within single data sets, different cohorts and nationalities exhibited differing trends. The two FpMULs were most common in the European (up to $40.75 \%$ of the subjects), Chinese (up to $48.27 \%$ ), and Japanese $(20.31 \%)$ metagenomes, whereas their prevalence was lower in North American (10.68\%) metagenomes. Among the two hunter-gatherer populations, the Yanomami and Hadza, we detected the presence of only FpMULL in one Yanomami and two Hadza individuals, indicating that these microbiomes may be able to degrade galactomannan derived from tubers that are part of their diet (25).

F. prausnitzii grows efficiently on $\beta$-mannooligosaccharides. Growth studies showed that $F$. prausnitzii SL3/3 failed to grow on KGM and CGM (Fig. 2a), likely reflecting the absence of a surface $\beta$-1,4-endomannanase required to generate suitable 
$\beta$-MOS for import into the cell. This hypothesis was confirmed by growing $F$. prausnitzii on both substrates predigested with a GH26 $\beta$-1,4-endomannanase from $R$. intestinalis (Fig. 2a). To assay for oligosaccharide generation and/or uptake, we used high-performance anion-exchange chromatography with pulsed amperometric detection (HPAEC-PAD) and determined the concentration of $\beta$-MOS in the initial and spent supernatant from $F$. prausnitzii cultures (Fig. 2b). Only polymeric $\beta$-mannan was observed in the spent supernatant after growth of the bacterium on KGM and CGM, demonstrating that F. prausnitzii does not display surface $\beta$-1,4-endomannanase activity. In contrast, F. prausnitzii was able to take up and utilize CGM- and KGM-derived $\beta$-MOS while mannose and mannobiose (M2) are seemingly untouched.

Taken together, these data support the concept that the two MULs are being expressed and the resulting proteins orchestrate the degradation of different $\beta$-MOS. To determine the biochemical basis for $\beta$-MOS import and deornamentation, the specificity of the $\beta$-MOS-binding protein, FpGH36, FpGH113, and the two CEs was determined. A model for catabolism of CGM- and KGM-derived $\beta$-MOS is presented in Fig. 3.

FpMOBP is a binding protein specific for $\beta$-MOS. In a previous study, we have shown that the binding protein RiMnBP of $R$. intestinalis is part of an $\mathrm{ABC}$ transporter that confers uptake of $\beta$-MOS with a degree of polymerization between 3 and 6 (7). The FpMUL harbors the components of an $A B C$ transporter similar to that of $R$. intestinalis, whereby FpMOBP is a $48-\mathrm{kDa}$ protein sharing $48 \%$ identity with RiMnBP. In order to confirm the expected role of FpMOBP in capturing $\beta$-MOS, we assessed the binding of the recombinantly produced protein to mannohexaose using isothermal titration calorimetry (ITC). FpMOBP bound to mannohexaose with a $K_{d}$ (dissociation constant) of $189 \pm 1.4 \mu \mathrm{M}$ $(\Delta G=-5.08 \pm 0.01 \mathrm{kcal} / \mathrm{mol} ; \Delta H=-19.8 \pm 0.28 \mathrm{kcal} / \mathrm{mol} ; T \Delta S=14.7 \pm 0.14 \mathrm{kcal} / \mathrm{mol} ; n=$ 0.8; corresponding thermograms are shown in Fig. S1a in the supplemental material). FpMOBP did not show any appreciable binding to cellohexaose (Fig. S1b), demonstrating the specificity of FpMOBP toward mannopyranosyl-linked ligands. Together, these data demonstrate that $F p M O B P$ is part of an ABC transporter specific for $\beta$-MOS.

FpGH113 is a reducing end mannose-releasing exo-oligomannosidase. FpGH113 is a $35-\mathrm{kDa}$ protein sharing $53 \%$ identity with $\mathrm{RiGH} 113$ from the previously characterized $\beta$-mannan utilization system in $R$. intestinalis (7) (Fig. 1). The closest structurally characterized homolog of $F p G H 113$ is the $\beta$-1,4-mannanase AxMan113A from Amphibacillus xylanus (26) with $48 \%$ identity between the two amino acid sequences. No signal peptide was identified by SignalP 4.0, suggesting that $F p G H 113$ is likely located intracellularly. The $F p G H 113$ enzyme released mannose and oligosaccharides from $6^{3}, 6^{4}-\alpha$-D-galactosyl-mannopentaose $\left(\mathrm{Gal}_{2} \mathrm{Man}_{5}\right.$ ) (Fig. S2a and b) and mannopentaose (Man ${ }_{5}$ (Fig. 4a), with mannose increasing over time (Fig. S2c), consistent with exo-activity. When the reducing end of $\mathrm{Man}_{5}$ was reduced with sodium borodeuteride $\left(\mathrm{NaBD}_{4}\right)$ (Fig. $\left.4 \mathrm{a}\right)$, no FpGH113 activity could be detected, demonstrating that this enzyme is a reducing end mannose-releasing exo-oligomannosidase. Considering the predicted intracellular location of FpGH113, we tested its activity against RiGH26-prehydrolyzed CGM. Consistent with this view, release of mannose was detected after overnight incubation of the enzyme with RiGH26-generated galacto- $\beta$-MOS (Fig. 4b), while FpGH113 was not able to hydrolyze intact CGM (Fig. S2d).

Removal of $\boldsymbol{\alpha}$-galactosyl and acetyl substitutions from $\boldsymbol{\beta}$-MOS. FpGH36 is a predicted intracellularly localized 79-kDa enzyme with two GH36 domains, located at the $\mathrm{N}$ and $\mathrm{C}$ termini of the protein, as well as an internal melibiase domain. The $F$. prausnitzii GH36 domains were all similar to those found in well-characterized $\alpha$-galactosidases, with AgaB from the thermophilic bacterium Geobacillus stearothermophilus being the closest structurally characterized homolog (44\% identity) (27). FpGH36 showed $42 \%$ identity to RiGH36 from $R$. intestinalis (Fig. 1). FpGH36 hydrolyzed $\alpha-1,6-$ galactose side chains from CGM-derived $\beta$-MOS (Fig. 4c) and Gal $_{2}$ Man $_{5}$ (Fig. S1a and b), exhibiting minor activity against polymeric galactomannan (Fig. 4c). This is consistent with the sequential activity of $F p G H 36$ on internalized galacto- $\beta$-MOS in vivo.

We have previously shown that in $R$. intestinalis the complete removal of acetyl substitutions on the $\beta$-MOS backbone is achieved through the complementary action of 


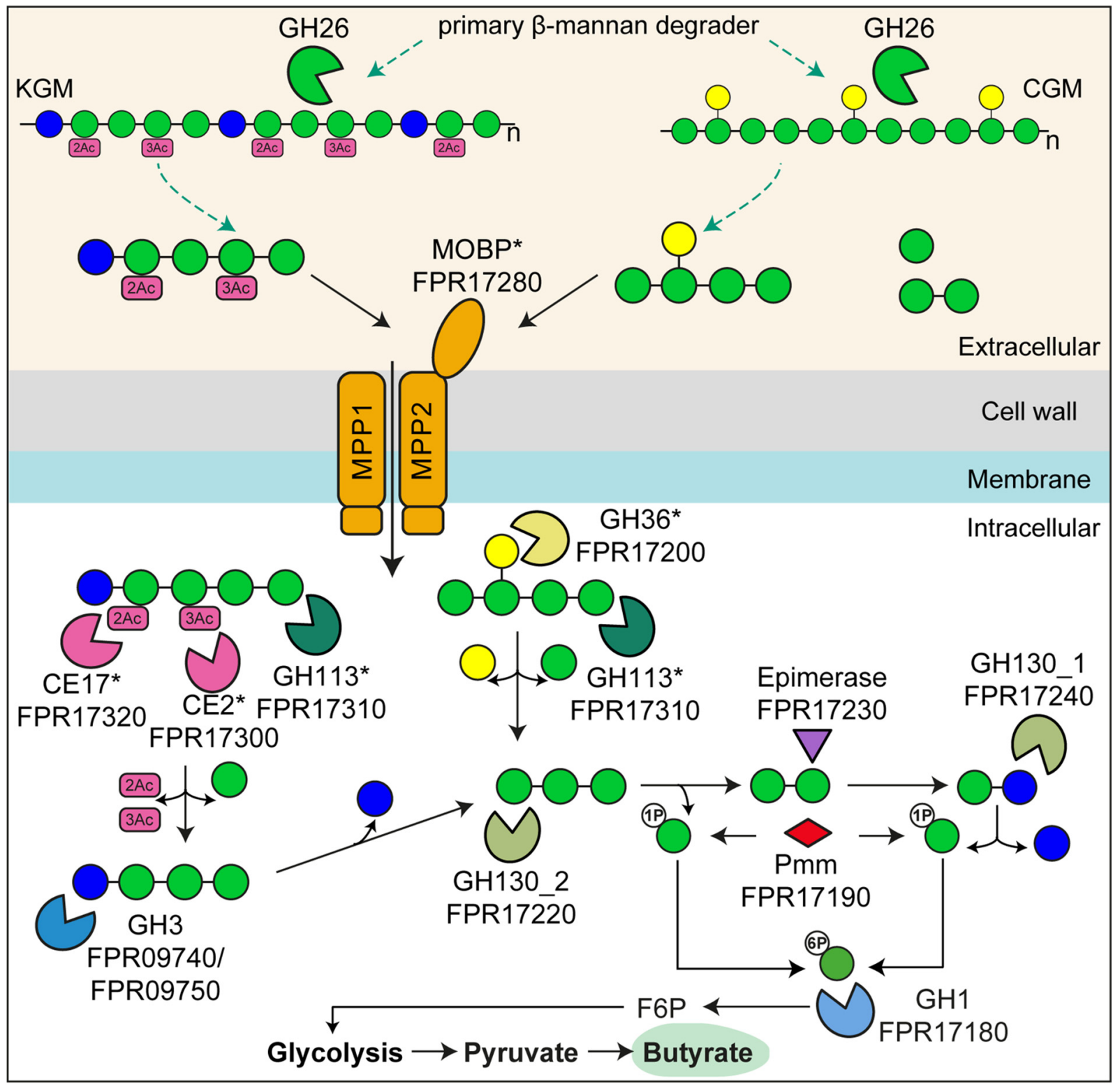

\section{Mannose Glucose Galactose

FIG 3 Schematic model of the $\beta$-MOS degradation pathway in F. prausnitzii. Gene products are colored as in Fig. 1. $\beta$-MOS liberated by $\beta$-mannan keystone species are bound on the surfaces of the $F$. prausnitzii cells by the MOBP-binding protein. The $\beta$-MOS transit intracellularly through the associated $\mathrm{ABC}$ transporter. Once intracellular, the $\alpha$-galactosidase $\mathrm{GH} 36$ and the reducing end mannose-releasing exo-oligomannosidase $\mathrm{GH} 113$ process the galactomannooligosaccharides into galactose, mannose, and mannotriose. The glucomannooligosaccharides are processed by the acetylesterases CE2 and CE17, two $\beta$-glucosidases (GH3), and the reducing end mannose-releasing exo-oligomannosidase GH113 into acetate, mannose, glucose, and mannotriose. The mannotriose is hydrolyzed by the $\beta$-1,4-mannooligosaccharide phosphorylase GH130_2 into mannose-1phosphate and mannobiose, which is then epimerized to mannosyl-glucose by an epimerase. A $\beta$-1,4-mannosylglucose phosphorylase GH130_1 phosphorolyses mannosyl-glucose into mannose-1-phosphate and glucose. The mannose-1-phosphate is converted into mannose-6-phosphate by a mannose phosphate mutase (Pmm) and further isomerized into fructose-6-phosphate by a GH1. This product, together with the other liberated monosaccharides and acetate, enters glycolysis that generates pyruvate, some of which is converted into butyrate. Proteins characterized in this study are indicated by asterisks.

two esterases, where RiCE2 attacks acetyl groups on either the 3-O, 4-O, or 6-O position, while RiCE17 attacks acetyl groups on the 2-O position (28). To explore whether F. prausnitzii employs a similar mechanism, KGM was prehydrolyzed with $\mathrm{RiGH}_{2} 6$ to generate glucomanno-oligosaccharides (GMOS) that were subsequently incubated 

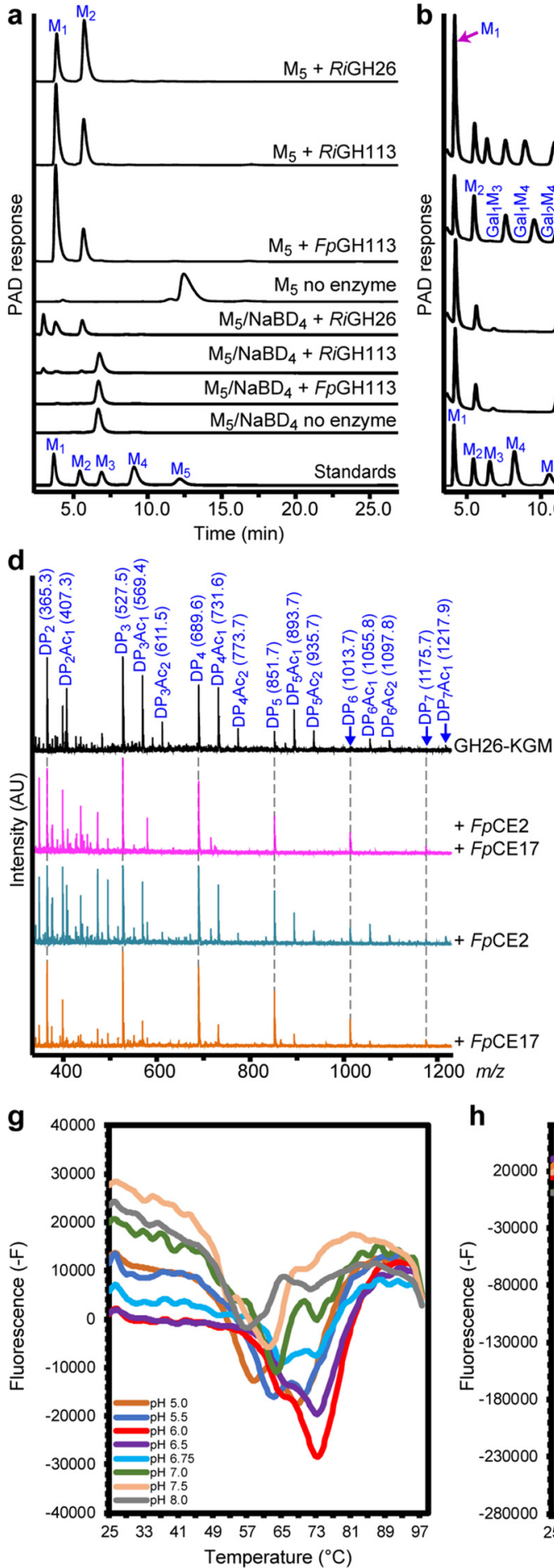
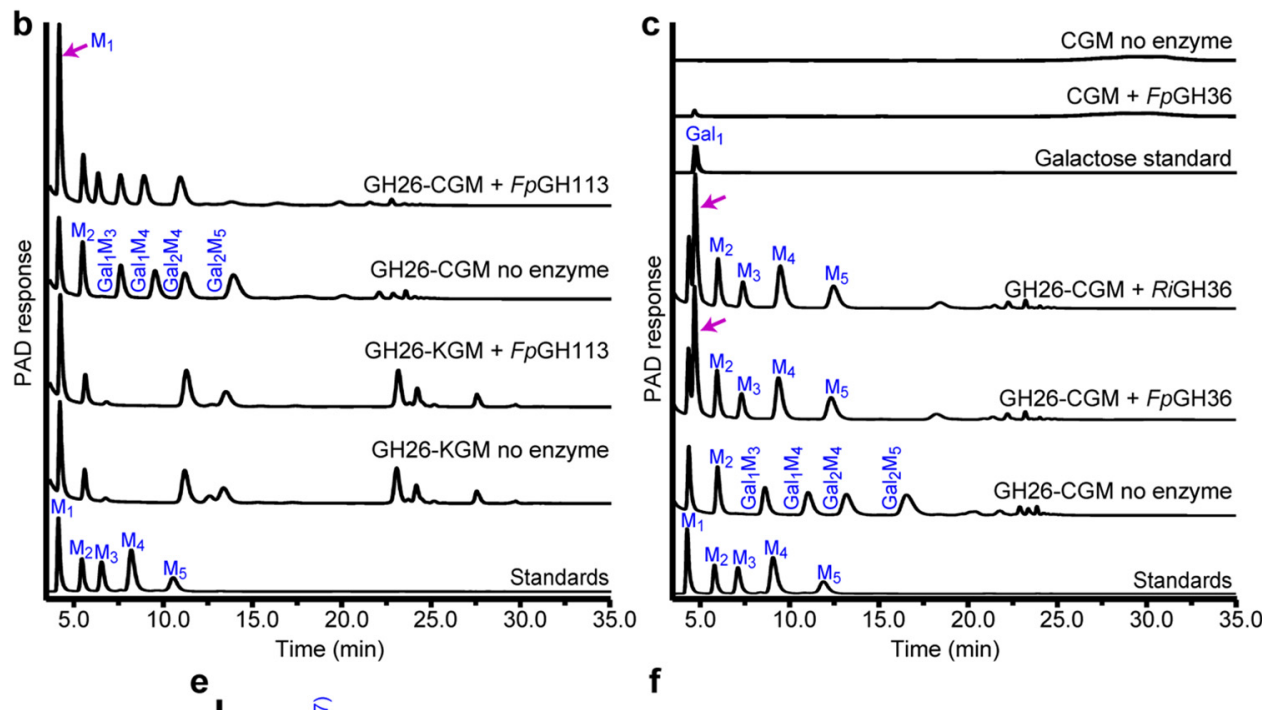
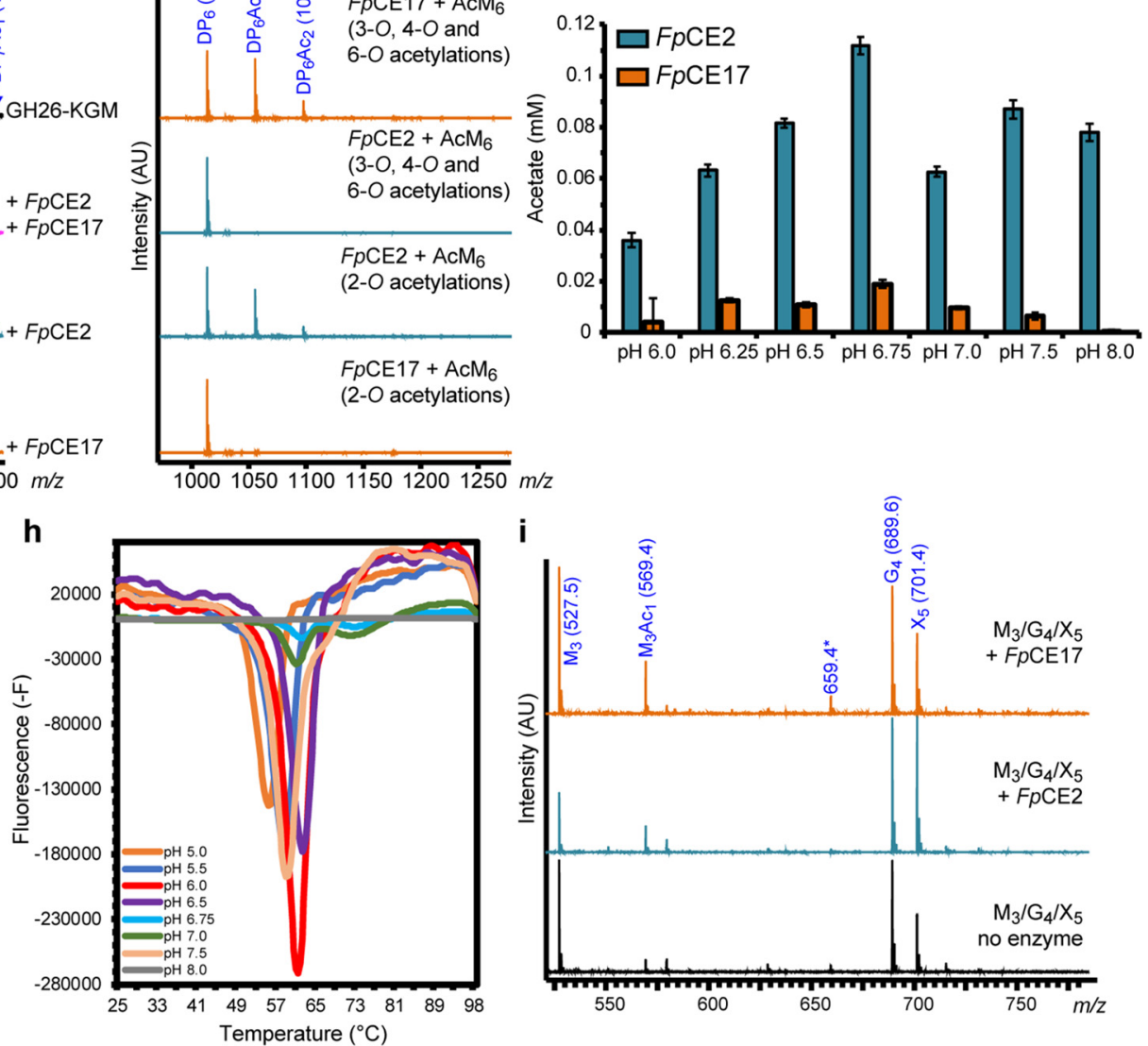

FIG 4 HPAEC-PAD and MALDI-ToF analysis of the activity of enzymes removing acetyl and galactosyl side chains and further hydrolyzing the imported $\beta$-MOS. (a) Mannose and $\beta$-MOS generated when FpGH113 was incubated with mannopentaose $\left(\mathrm{M}_{5}\right)$. FpGH113 was unable to hydrolyze $\mathrm{M}_{5}$ that had been pretreated with sodium borodeuteride $\left(\mathrm{NaBD}_{4}\right)$ to convert the reducing end monosaccharide unit into its alditol. Control reaction with the previously characterized reducing end mannose-releasing exo-oligomannosidase RiGH113 and endo-mannanase RiGH26 are shown. (b) HPAEC-PAD traces of the product generated before and after hydrolysis of RiGH26-pretreated carob galactomannan (GH26-CGM) and RiGH26-pretreated konjac glucomannan (GH26KGM) with FpGH113. (c) HPAEC-PAD trace showing the oligosaccharide products of CGM digestion with RiGH26 and subsequently incubated with FpGH36 $\alpha$-galactosidase. (d) MALDI-ToF spectra showing products (as sodium adducts) generated after incubation of predigested KGM (RiGH26-KGM) with either FpCE17 or FpCE2 or both enzymes in combination. Peaks are labeled by degree of polymerization (DP) and number of acetyl (Ac) groups. Intensity is shown in arbitrary units (AU). (e) Mass spectra of mannohexaose containing acetylations at different positions after treatment with either FpCE17 or FpCE2. These substrates were generated in-house using the $R$. intestinalis esterases RiCE2 and RiCE17. The annotated $\mathrm{m} / \mathrm{z}$ values indicate sodium adducts. (f) pH optima of FpCE17 or FpCE2. pH optima were determined on pNP acetate in $50 \mathrm{mM}$ sodium phosphate buffers with different pHs at room temperature.

(Continued on next page) 
TABLE 1 Deacetylation rate, specific activity, and turnover rates of $F p C E 2$ and $F p C E 17$ on AcGGM from Norway spruce ${ }^{a}$

\begin{tabular}{llll}
\hline Parameter & FpCE17 & FpCE2 & FpCE17+FpCE2 \\
\hline Deacetylation rate $(\mathrm{nmol} / \mathrm{s})$ & 4,166 & 16,550 & 7,588 \\
$k_{\text {cat }}\left(\mathrm{s}^{-1}\right)$ & 83 & 331 & 152 \\
sp act $(\mathrm{nmol}$ acetate/s/ $\mu \mathrm{g}$ enzyme) & 2 & 8 & \\
\hline
\end{tabular}

${ }^{a}$ Values are calculated based on the acetate released in the initial $15 \mathrm{~min}$ of reaction.

with FpCE2 (32\% amino acid sequence identity with RiCE2) and FpCE17 (46\% amino acid sequence identity with RiCE17). Matrix-assisted laser desorption ionization-time of flight mass spectrometry (MALDI-ToF MS) analysis of products released from GMOS revealed that the two enzymes mediated the complete removal of acetylations when added together, while a partial deacetylation was observed when the substrate was treated with each of the enzymes separately (Fig. 4d). To explore the extent to which this strategy for complete substrate deacetylation is conserved in Firmicutes, we exploited the transacetylation specificity of $R$. intestinalis esterases (28) to generate acetylated mannohexaoses $\left(\mathrm{AcM}_{6}\right)$ and tested the activity of FpCE2 and FpCE17 on these substrates. FpCE2 was able to deacetylate only the RiCE2-generated $\mathrm{AcM}_{6}$, thus demonstrating that this enzyme removes 3-O-, 4-O-, and 6-O-acetylations (Fig. 4e). FpCE17 was effective on RiCE17-generated $\mathrm{ACM}_{6}$ and displayed no activity on RiCE2-generated $\mathrm{AcM}_{6}$, thus showing that $\mathrm{FpCE} 17$ exclusively removes the axially oriented 2-O-acetylations (Fig. 4e). Taken together, these results prove that the F. prausnitzii esterases have the same acetylation site specificity as their corresponding enzymes in $R$. intestinalis.

To further characterize the two F. prausnitzii esterases, we evaluated their activity both on a commercial substrate, i.e., para-nitrophenyl (pNP) acetate, and on a natural substrate, i.e., RiGH26 hydrolyzed acetylated galactoglucomannan (AcGGM). When tested on pNP acetate, both FpCE2 and FpCE17 were most active at pH 6.75 (Fig. 4f). Deacetylation rate measurements on RiGH26-prehydrolyzed AcGGM at $\mathrm{pH} 6.75$ and $35^{\circ} \mathrm{C}$, conditions that prevent acetyl migration, at equal enzyme loadings ( $50 \mathrm{nM}$ ) indicated that FpCE2 releases acetate approximately four times faster than FpCE17 (Table 1). When combined, using $25 \mathrm{nM}$ of each esterase, the deacetylation rate, $k_{\text {cat }}$ and specific activity were approximately two-fold higher than the values from treatments with FpCE17 and two-fold lower than the values from treatments with the FpCE2 when used on its own, respectively (Table 1).The reduced resulting rate of deacetylation suggests that the esterases are not acting synergistically but may rather be competing for the substrate, a behavior previously reported in cocktails of multiple enzymes for lignocellulose hydrolysis (29).

Melting curves for both enzymes in buffers at pH 5.0 to 8.0 were obtained using a protein thermal shift assay (Fig. $4 \mathrm{~g}$ and h). Both FpCE2 and FpCE17 displayed an irreversible thermal unfolding transition, which is consistent with their multidomain structure $(28,30) . F p C E 17$ was stable up to $73^{\circ} \mathrm{C}$, with the highest observed melting temperature at $\mathrm{pH} 6.0$; its lowest observed melting temperature was $58^{\circ} \mathrm{C}$ at $\mathrm{pH} 5$. For FpCE2, the unfolding took place at higher temperature, with a melting point of $62^{\circ} \mathrm{C}$ at $\mathrm{pH} 6.0$ and a highest melting point of $73^{\circ} \mathrm{C}$ at pH 7.0 and 8.0 (Fig. $4 \mathrm{~g}$ and h); its lowest observed melting temperature was $56^{\circ} \mathrm{C}$ at $\mathrm{pH} 5.0$.

Studies of substrate specificities have shown that acetyl esterases are able to efficiently catalyze the transfer of an acetyl group from a donor, such as vinyl acetate, to precise positions of an oligosaccharide with the generation of highly specific esterified

FIG 4 Legend (Continued)

Acetate release was measured after a 10-min incubation. (g) Thermal shift assay melting curve for FpCE17. (h) Thermal shift assay melting curve for FpCE2. Both in panels $\mathrm{g}$ and $\mathrm{h}$, plots show derivative fluorescence data $(-\mathrm{F})$ as a function of temperature $\left({ }^{\circ} \mathrm{C}\right)$. (i) MALDI-ToF MS analysis of reactions for identification of preferred oligosaccharides for FpCE2 and FpCE17. The esterases were tested on a mix with mannotriose $\left(\mathrm{m} / \mathrm{z} 527 ; \mathrm{M}_{3}\right)$, cellotetraose $(\mathrm{m} / \mathrm{z}$ $\left.689 ; G_{4}\right)$, and xylopentaose $\left(\mathrm{m} / \mathrm{z} 701 ; \mathrm{X}_{5}\right)$ and with vinyl acetate, vinyl propionate, and vinyl butyrate as ester donors. In all panels, data are representative of independent triplicates. Abbreviations: $M_{1}$, mannose, $M_{2}$, mannobiose; $M_{3}$, mannotriose; $M_{4}$, mannotetraose; $M_{5}$, mannopentaose; $M_{6}$, mannohexaose, $\mathrm{Gal}_{1}$, galactose; Gal $\mathrm{M}_{3}$, galactosylmannotriose; Gal $\mathrm{M}_{4}$, galactosylmannotetraose; $\mathrm{Gal}_{2} \mathrm{M}_{4}$, digalactosylmannotetraose; Gal ${ }_{2} \mathrm{M}_{5}$, digalactosylmannopentaose. 
oligosaccharides (28). Consistent with that notion, we found that both $F$. prausnitzii esterases were able to transacetylate mannotriose $\left(M_{3}\right)$ and mannotetraose (data not shown). To further test the preferred substrate for the esterases, we incubated either FpCE17 or FpCE2 with a mix of $\mathrm{M}_{3}$, cellotetraose $\left(\mathrm{G}_{4}\right)$, and xylopentaose $\left(\mathrm{X}_{5}\right)$ and used vinyl acetate as an acetyl donor. MALDI-ToF MS analysis of products generated by these reactions showed that the esterases transferred the acetyl group only to $M_{3}$ (Fig. 4i), thus confirming the manno-oligosaccharide specificity of FpCE17 and FpCE2.

Cocultivation of $\boldsymbol{F}$. prausnitzii with primary $\boldsymbol{\beta}$-mannan degraders. The data presented above suggest that $F$. prausnitzii has a sufficiently complex enzymatic toolbox to benefit from the uptake of $\beta$-MOS liberated in the surrounding environment by other gut microbes. To test this hypothesis and evaluate the competitiveness of this strain in the utilization of $\beta$-MOS, we cocultured $F$. prausnitzii with two keystone commensal organisms for $\beta$-mannan utilization, namely, the Gram-negative Bacteroidetes B. ovatus strain V975 and the Gram-positive Firmicutes $R$. intestinalis strain L1-82. F. prausnitzii grew in the presence but showed poor growth in the absence of B. ovatus on intact KGM (Fig. 5a). The optical densities obtained when $F$. prausnitzii was grown in monoculture in the no-carbon source control (Fig. 5b) were similar to those obtained in KGM, suggesting that the microbe is not able to utilize this glycan on its own. Notably, the maximum optical density at $650 \mathrm{~nm}\left(\mathrm{OD}_{650}\right)$ of the coculture $\left(\mathrm{OD}_{650}=0.55\right)$ appeared higher in the $\beta$-mannan polymer than those observed for $B$. ovatus in single culture $\left(\mathrm{OD}_{650}=0.49\right)$, indicating that syntrophic growth exists between these two populations under these conditions (Fig. 5a). The two strains showed comparable growth on glucose (Fig. 5c). F. prausnitzii is a butyrate producer, while carbohydrate fermentation by $B$. ovatus results in the production of propionate (5). Therefore, comparing differences in butyrate levels between the single $F$. prausnitzii culture and coculture may provide evidence as to whether cross-feeding of $\beta$-mannan breakdown products by $F$. prausnitzii occurred. Butyrate concentrations were significantly increased $(P=0.001)$ in the coculture compared to the monococulture in KGM (Fig. $5 \mathrm{~d}$ ), the coculture in minimal medium with no carbon source (Fig. 5e) or glucose (Fig. 5f), which suggests that F. prausnitzii can effectively compete for $\beta$-MOS generated by the cell-surface-exposed endo-mannanase BoMan26B from $B$. ovatus (31). This effect required the presence of living $B$. ovatus cells, as no evidence of an increase of butyrate levels was detected when $F$. prausnitzii was cogrown with a heat-treated B. ovatus culture (Fig. S3). Population estimates using quantitative PCR (qPCR) showed that, while no growth was observed when F. prausnitzii was cultivated singly on KGM, it grew well in the coculture supplemented with KGM (Fig. $5 \mathrm{~g}$ ), thus indicating cross-feeding activity by $F$. prausnitzii. Both $F$. prausnitzii and B. ovatus displayed similar growth on glucose (Fig. 5h), suggesting that the bacteria shared the available carbon source and maintained coexistence. When $F$. prausnitzii was cocultured with $R$. intestinalis in KGM, in the absence of a carbon source or in glucose, the growth curves appeared very similar to when $R$. intestinalis was cultured on its own (Fig. $5 \mathrm{i}$ to $\mathrm{k}$ ). As both bacteria produce butyrate, we compared the value observed in the coculture to the sum of butyrate concentration in both single cultures. No significant increase $(P>0.05)$ of butyrate concentrations was observed in the coculture compared to the single cultures in KGM (Fig. 5l), minimal medium (Fig. $5 \mathrm{~m}$ ), or minimal medium plus glucose (Fig. $5 \mathrm{n}$ ). Intriguingly, while no growth was observed in monococulture in KGM, F. prausnitzii displayed growth in coculture with R. intestinalis (Fig. 50), thus demonstrating cross-feeding behaviors. When growing in coculture on glucose, $R$. intestinalis dominated the culture and outcompeted $F$. prausnitzii (Fig. 5p). Notably, cocultivation of F. prausnitzii with either B. ovatus (Fig. 5b) or R. intestinalis (Fig. 5j) without any carbon source resulted in no increase in the overall levels of butyrate in the cocultures (Fig. 5e and m). These data indicate the specific effect of KGM degradation products to support $F$. prausnitzii growth and exclude the possibility that this microbe is cross-feeding on bacterial-derived components (such as capsular polysaccharides).

\section{DISCUSSION}

Biochemical work presented herein demonstrates that two MULs support the ability of $F$. prausnitzii to utilize $\beta$-MOS. $\beta$-MOS from diet are highly variable with respect to 

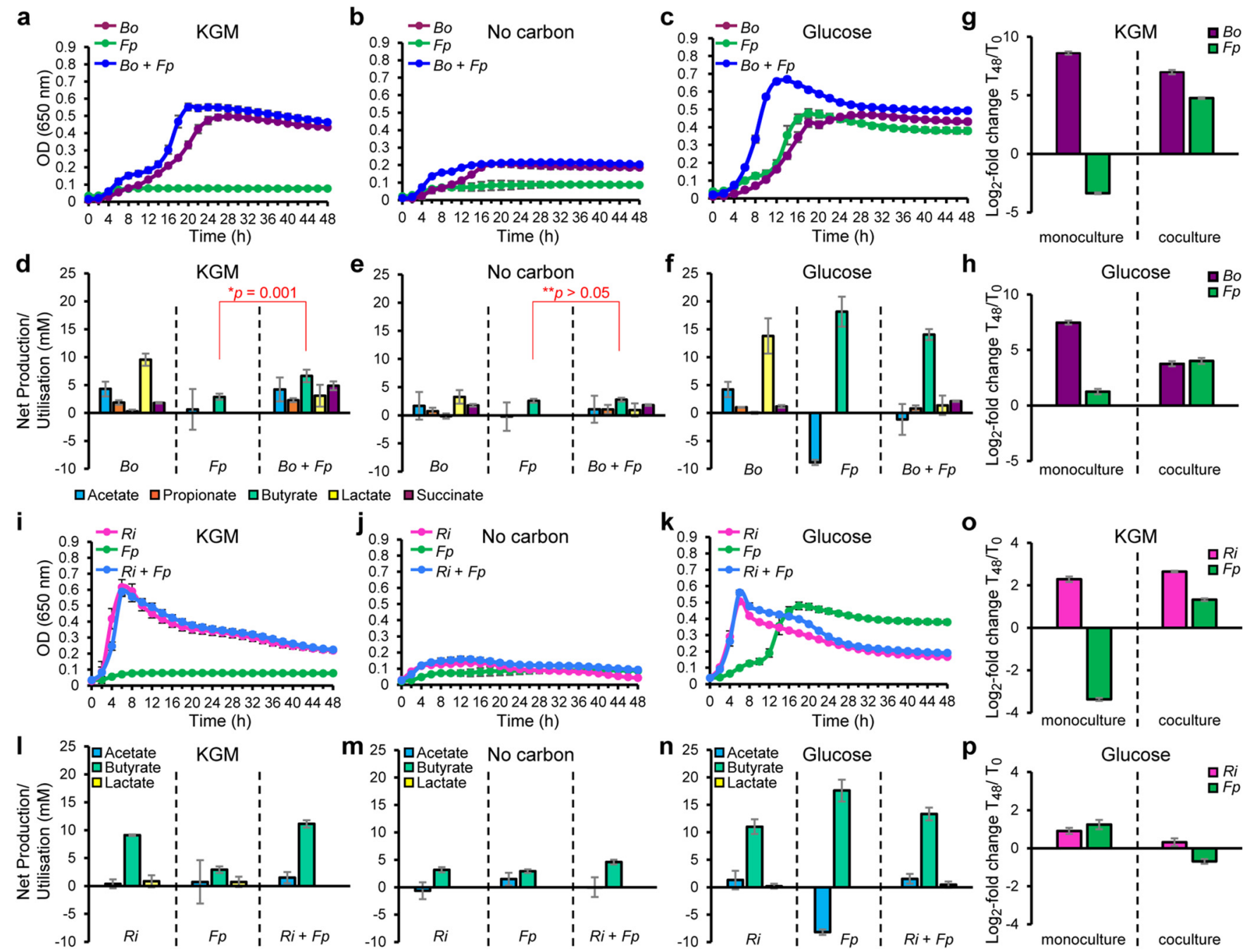

FIG 5 Cocultivation experiments of $F$. prausnitzii with keystone $\beta$-mannan degraders. (a to c) Growth kinetics of mono- and cocultures of $F$. prausnitzii (Fp) and $B$. ovatus $(B o)$ in $M 2$ medium containing $0.2 \%$ konjac glucomannan (KGM) (a), no carbon source (no carbon) (b), or $0.2 \%$ glucose (c). (d to $f$ ) Fermentation products for mono- and cocultures of $F$. prausnitzii ( $F p$ ) and B. ovatus (Bo) (d), KGM with no carbon source (e) or glucose (f). 16S rRNA genetargeted qPCR data signifying changes in relative abundance for $F$. prausnitzii $(F p)$ and $B$. ovatus (Bo) in monococulture and coculture in KGM (g) or glucose (h). (i to k) Growth of single and cocultures of $F$. prausnitzii $(F p)$ and $R$. intestinalis (Ri) in M2 medium supplemented with $0.2 \%$ konjac glucomannan (KGM) (i), no carbon source (j), or glucose (k). (I to $\mathrm{n}$ ) Concentration of different metabolites in the spent media of single and cocultures of $F$. prausnitzii ( $F p$ ) and $R$. intestinalis (Ri) in M2 medium with $0.2 \%$ konjac glucomannan (KGM) (I), no carbon source (m), or glucose (n). (o and p) $16 \mathrm{~S}$ rRNA gene-targeted qPCR data signifying changes in relative abundance, for $F$. prausnitzii $(F p)$ and $R$. intestinalis $(R i)$ in monococulture and coculture in $\mathrm{KGM}$ (o) or glucose (p). In panels $\mathrm{g}, \mathrm{h}, \mathrm{o}$, and $\mathrm{p}$, the number of $16 \mathrm{~S}$ rRNA gene copies per milliliter of culture, obtained using qPCR, at the start (T0) and end (T48) of the experimental run were expressed as T48/T0 to obtain fold changes which were then $\log _{2}$ transformed. In all panels, the data are means with standard deviations of a minimum of three replicates. For calculation of SCFA concentrations, the values measured in uninoculated M2, glucose, and KGM media were subtracted from the sample values. Statistically significant differences for butyrate concentration were determined with the Mann-Whitney test using SCFA data.

sugar composition and linkages, and the F. prausnitzii enzymatic apparatus is adapted to deal with this diversity. Our findings show that $\beta$-MOS are bound by FpMOBP at the cell surface and subsequently imported intracellularly; here, they are further saccharified by FpGH113 and degalactosylated and deacetylated by the combined action of FpGH36, FpCE2, and FpCE17 (Fig. 3). By analogy with the model described for $R$. intestinalis (7), putative $\beta$-glucosidases of GH3 may confer the removal of terminal glucose residues in gluco- $\beta$-MOS prior to depolymerization of the remaining linear $\beta$-MOS by the activity of a putative mannooligosaccharide phosphorylase (FpGH130_2) into mannobiose. Mannobiose is subsequently epimerized into mannosyl-glucose by a putative epimerase, FpMep, and phosphorolysed by FpGH130_1 into glucose and mannose-1-phosphate, similar to the pathway described for Ruminococcus albus (32). As shown for R. intestinalis 
(7), the end products of this pathway enter glycolysis either directly (glucose) or after being converted to mannose-6-phosphate and fructose-6-phosphate by the phosphomannose mutase $\mathrm{FpPmm}$ and the isomerase $\mathrm{FpGH1}$, respectively. Released galactose and mannose are converted to galactose-1-phosphate (via the Leloir pathway) and mannose-6-phosphate (by a hexokinase) before entering glycolysis (7). The pyruvate generated from glycolysis is then partly converted to butyrate (33). A comparative genomic analysis revealed that the FpMULs are widespread and highly conserved among human gut-associated F. prausnitzii (Fig. 1a). The presence of genes associated with conjugation and phage-related events in the flanking regions suggests that the FpMULL was acquired through horizontal gene transfer from other gut bacteria, as previously observed for PULs identified in commensal Bacteroides genomes (34).

Members of the dominant Bacteroides genus, such as B. ovatus, as well as Firmicutes species, like Roseburia, that possess GH26 endomannanases have been described as the keystone bacteria for $\beta$-mannan degradation in the gut $(7,21,31)$. In contrast, F. prausnitzii may only access oligosaccharides, released by these primary degraders, which can be imported without the need for extracellular enzymatic cleavage. In this context, we demonstrate that $\beta$-MOS are indeed released into the culture medium by $B$. ovatus during cogrowth on KGM and that $F$. prausnitzii is capable of efficiently competing for and utilizing these oligosaccharides (Fig. $5 \mathrm{~g}$ ). Similarly, we observed evidence of cooperative growth between $R$. intestinalis and $F$. prausnitzii when cocultured in KGM (Fig. 5o). We recently demonstrated the competitiveness of $R$. intestinalis on $\beta$-mannan when in coculture with $B$. ovatus during growth on AcGGM (7), and highlighted a pivotal role of a transport protein (RiMnBP) within the uptake system, which exhibited strong binding to short $\beta$-MOS (degree of polymerization [DP], 3 to 6) with different side chain decoration patterns (7). Similar observations were recently reported for the Bifidobacterium genus, with B. animalis subsp. lactis ATCC 27673 outcompeting $B$. ovatus during growth on galactomannan (35). Notably, the two $B$. animalis binding proteins, $B / M n B P 2$ and $B / M n B P 1$, mediated high-affinity capture of $\beta$-MOS with preference to oligosaccharides with a DP of 3 to 4 and $K_{d}$ values in the 70 to $80 \mathrm{nM}$ range (35). In contrast, the SusD-like $\beta$-MOS-binding proteins from $B$. ovatus displayed binding to $\mathrm{M}_{6}\left(K_{d}\right.$ value of $\left.1.8 \pm 0.2 \mathrm{mM}\right)(31)$ with about 10-fold lower affinity than that of FpMOBP, 53-fold lower affinity than that of RiMnBP, and about 900 -fold lower affinity than that of B/MnBP2 and B/MnBP1. The results shown in Fig. $5 \mathrm{~g}$ and 0 show that the growth of $F$. prausnitzii was much more pronounced when in cocultures with $B$. ovatus (Fig. $5 \mathrm{~g}$ ) (with an average 16S rRNA gene copies per $\mathrm{ml}$ of culture of $5.91 \mathrm{E}+8$ F. prausnitzii and 1.34E +09 B. ovatus, corresponding to a ratio of 2.3:1 B. ovatus-F. prausnitzii) than in F. prausnitzii-R. intestinalis cocultures (Fig. 5o) (with an average $16 \mathrm{~S}$ rRNA gene copies per $\mathrm{ml}$ of culture of $1.24 \mathrm{E}+8$ F. prausnitzii and $6.94 \mathrm{E}+8$ R. intestinalis, corresponding to a ratio of 5.6:1 R. intestinalis-F. prausnitzii). This is consistent with the fact that $F$. prausnitzii FpMOBP is more efficient in capturing oligosaccharides from the "weaker" binding of SusD-like $\beta$-MOS-binding protein of B. ovatus than from the $R$. intestinalis RiMnBP. Thus, the differential transporter affinity to $\beta$-MOS provides a possible rationale for the trophic interactions established by $F$. prausnitzii with Bacteroides, enabling efficient capture of communally available nutrients within synthetic consortia, and potentially in natural gut communities. On the other hand, the binding affinity of MnBPs plausibly gives a reason as to why cross-feeding on KGM was present to a lower extent in the $R$. intestinalis and $F$. prausnitzii coculture and why the affinity of RiMnBP to $\mathrm{M}_{6}\left(K_{d}\right.$ value of $\left.33.75 \pm 0.95 \mu \mathrm{M}\right)$ was five times stronger than that of FpMOBP. This difference is likely to be crucial for selfish resource capture by the keystone $\beta$-mannan primary degrader $R$. intestinalis (7) with minimal loss of valuable nutrients in a competitive environment.

To understand the capacity of human populations to derive nutrition from $\beta$-MOS, we surveyed 2,441 publicly available human metagenomes and revealed that MULs closely related to those of $F$. prausnitzii are widely distributed throughout human populations (Fig. 1b). Indeed, we did not observe correlation with any particular 
population or nation, consistent with the fact that dietary $\beta$-MOS/ $\beta$-mannan are a ubiquitous component of the human diet. The FpMULs were more common than population restricted traits like red algal porphyran degradation, known to be confined to a small cohort of Japanese subjects and absent in the microbiome of Western individuals (34), but they were less common than Bacteroides-associated PULs for degradation of plant cell wall xyloglucan (92\% of samples) (36), mixed-linkage $\beta$-glucans $(92.5 \%$ of samples) (37), $\beta$-(1,3)-glucans (59\% of samples) (38), and yeast $\alpha$-mannans (62\% of samples) (39). Moving beyond the human microbiota, we detected two analogous FpMULs in a F. prausnitzii strain found in the porcine gut microbiota (40). Proteomic analysis identified FpMUL-encoded proteins being more abundant in pigs fed a diet supplemented with $4 \%$ AcGGM, thus providing evidence that these analogous MULs are employed by F. prausnitzii inhabiting environments beyond the human gut (40).

In conclusion, biochemical and microbiological data presented in this study illustrate that $F$. prausnitzii possesses an extensive enzymatic apparatus that targets $\beta$-MOS released by neighboring colonic bacteria. ITC data provide evidence that the external recognition machinery is tailored for the capture of $\beta$-MOS with stronger affinity than Bacteroides. This is in line with the fact that, when in coculture, F. prausnitzii showed cross-feeding behaviors with $B$. ovatus, whose own $\beta$-MOS uptake requires a SusD-like protein that binds oligosaccharides with about 10-fold-lower affinity than that of FpMOBP. Furthermore, this study in conjunction with a previous report (7) points to a competitive mechanism of $\beta$-MOS/ $\beta$-mannan utilization in the gut microbiota where keystone Lachnospiraceae members like $R$. intestinalis have developed a sophisticated "selfish" uptake and degrading system to minimize sharing resources with Bacteroides and Ruminococcaceae species such as F. prausnitzii.

Overall, our study contributes toward the understanding of cross-feeding mechanisms deployed by a beneficial commensal microorganism to interact with dietary $\beta$-mannan. Significantly, these findings could help to design prebiotic/symbiotic formulations that are optimized for selective manipulation of gut microbiome functions in ways that promote human health and beyond.

\section{MATERIALS AND METHODS}

Substrates. All glycan stocks were prepared at $10 \mathrm{mg} / \mathrm{ml}$ in double-distilled water $\left(\mathrm{ddH}_{2} \mathrm{O}\right)$ and sterilized by filtration using a $0.22-\mu \mathrm{m}$ membrane filter (Sarstedt AG \& Co., Germany).

(i) Polysaccharides. Konjac glucomannan and carob galactomannan were purchased from Megazyme International (Wicklow, Ireland).

(ii) Oligo- and monosaccharides. Mannose $\left(M_{1}\right)$ and glucose $\left(G_{1}\right)$ were purchased from SigmaAldrich (St. Louis, MO, USA). Xylopentaose $\left(X_{5}\right)$, cellobiose $\left(G_{2}\right)$, cellotetraose $\left(G_{4}\right)$, mannobiose $\left(M_{2}\right)$, mannotriose $\left(M_{3}\right)$, mannotetraose $\left(M_{4}\right)$, mannopentaose $\left(M_{5}\right)$, mannohexaose $\left(M_{6}\right), 6^{1}$ - $\alpha$-D-galactosyl-mannotriose $\left(\mathrm{GaIM}_{3}\right)$, and $6^{3}, 6^{4}$ - $\alpha$-D-galactosyl-mannopentaose $\left(\mathrm{Gal}_{2} \mathrm{M}_{5}\right)$ were purchased from Megazyme. Konjac glucomannan digest and carob galactomannan digest were produced in-house using RiGH26 (7) in $10 \mathrm{mM}$ sodium phosphate ( $\mathrm{pH}$ 5.8). Reaction mixtures were incubated for $16 \mathrm{~h}$ at $37^{\circ} \mathrm{C}$ following removal of RiGH26 using a Vivaspin 20 filtration unit (10,000-molecular-weight-cutoff [MWCO] polyethersulfone [PES]; Sartorius) and carbohydrate lyophilization on an ALPHA 2-4 LD Plus freeze dryer (Christ, Germany). Acetylated galactoglucomannan (AcGGM) was produced in-house as described by La Rosa et al. (24).

Bacterial strains and culture conditions. Faecalibacterium prausnitzii SL3/3, Roseburia intestinalis L1-82, and Bacteroides ovatus V975 were routinely cultured with $\mathrm{CO}_{2}$ at $37^{\circ} \mathrm{C}$ in $\mathrm{M} 2$ medium containing $30 \%$ clarified rumen fluid supplemented with $0.2 \%(\mathrm{wt} / \mathrm{vol})$ glucose, soluble potato starch, and cellobiose (GSC) (41). These bacterial isolates were from stocks held by the authors (S. H. Duncan, Rowett Institute of Nutrition and Health, Aberdeen, United Kingdom), and all are of human fecal origin (23, 42, 43). Growth measurements on individual substrates were performed in M2GSC medium containing a single carbohydrate at $0.2 \%$ (wt/vol) final concentration using 96 -well plates in a Don Whitley MACS-VA500 workstation $\left(80 \% \mathrm{~N}_{2}, 10 \% \mathrm{H}_{2}\right.$, and $\left.10 \% \mathrm{CO}_{2}\right)$. Growth was assessed by measuring the absorbance at $650 \mathrm{~nm}$ (optical density at $650 \mathrm{~nm}\left[\mathrm{OD}_{650}\right]$ ) at 2-h intervals for up to $24 \mathrm{~h}$ using an Epoch 2 microplate reader (BioTek, VT, USA). The competition assays of $F$. prausnitzii and either $B$. ovatus or $R$. intestinalis were conducted by growing the strains as described above in the presence of $0.2 \%$ (wt/vol) konjac glucomannan. The strains inoculated into M2 medium with no added carbohydrate source and M2 medium with $0.2 \%(\mathrm{wt} / \mathrm{vol})$ glucose were included as negative and positive controls, respectively. Five-microliter samples of overnight bacterial cultures from both strains were used to inoculate the wells (final volume of $200 \mu \mathrm{l})$. The cocultures were incubated at $37^{\circ} \mathrm{C}$ anaerobically, and growth was followed by measuring the $\mathrm{OD}_{650}$ for 24 to $48 \mathrm{~h}$. Samples were collected at the end of the experiment, cells were pelleted for subsequent DNA extraction, and the supernatant $(500 \mu \mathrm{l})$ was used for SCFA analysis. All growth experiments were performed in triplicate. 
DNA extraction and quantitative PCR. After the growth experiments involving single cultures and cocultures were completed, cell pellets were obtained from triplicate wells for each condition tested $(600 \mu \mathrm{l})$ and the bacterial inoculum $(600 \mu \mathrm{l})$. The cell pellets were resuspended in $978 \mu \mathrm{l}$ sodium phosphate buffer and $122 \mu \mathrm{l}$ MT buffer and stored at $-70^{\circ} \mathrm{C}$ until DNA extraction, which was performed using the FastDNA SPIN kit for Soil (MP Biomedicals, Irvine, CA, USA) following the manufacturer's instructions. The extracted DNA from the mono- and coculture experiments was analyzed using quantitative PCR as described by Chung et al. (44) with some modifications. Herring sperm (HS) DNA (5 ng/ml) (Promega, Madison, WI, USA) was used to dilute the samples and 16S PCR products of reference strains to obtain a 10-fold dilution series for standard curves. A master mix containing iTaq Universal SYBR green Supermix (Bio-Rad, Hemel Hempstead, UK), $10 \mu \mathrm{M}$ primer pairs (500 nM final concentration), and molecular biology grade water was prepared. The master mix $(8 \mu \mathrm{l})$ together with $2 \mu \mathrm{l}$ of either a diluted sample $(1 \mathrm{ng} / \mu \mathrm{l})$ or standard, giving a total volume of $10 \mu \mathrm{l}$, was distributed into the wells of 384-well plates. The plates were then sealed with optical seals (Bio-Rad). Samples were amplified with universal primers (UniF and UniR) against total bacteria and specific primers targeting Roseburia spp. (44), Bacteroides spp. (44), and F. prausnitzii. Specific primers against F. prausnitzii (100.85\% $\pm 1.53 \%$ efficiency) were designed as part of this study (see Table $\$ 2$ in the supplemental material). The Bio-Rad CFX384 real-time system was used for the amplification of samples and standards using the protocol described previously with annealing temperatures appropriate for each primer set (Table S2). The reactions were performed in duplicate, and the number of 16S rRNA gene copies per milliliter of culture for each bacterial strain in the mixes tested were determined using information from the standard curves. Negative controls containing only herring sperm (HS) DNA were used to determine the detection limit.

Bioinformatics, cloning, expression, and purification of recombinant proteins. F. prausnitzii SL3/ 3's FpMULL and FpMULS were identified by tBLASTn-based homology searches using the amino acid sequences of the proteins from the previously characterized $R$. intestinalis $\beta$-mannan degradation system as the query (7). The genes encoding mature forms of the proteins described in this study were amplified from the $F$. prausnitzii SL3/3 genomic DNA (BioProject accession number PRJNA39151) by PCR using appropriate primers (Table S1). All primers were designed to amplify constructs to exclude predicted signal peptides (predicted by the SignalP v4.1 server [45]). PCR products were generated using the Q5 High-Fidelity DNA polymerase (New England BioLabs, United Kingdom) with 50 ng genomic DNA as the template. The PCR products were cloned into pNIC-CH (Addgene plasmid 26117) by ligation-independent cloning (46). All constructs were designed to harbor a C-terminal $\mathrm{His}_{6}$ tag fusion in the translated recombinant peptide, although for FpGH36, His tag translation was prevented by the introduction of one stop codon at the end of the open reading frame. Successful generation of constructs was verified by sequencing (Eurofins, UK). Plasmids harboring the gene of interest were transformed into chemically competent Escherichia coli BL21 STAR cells (Invitrogen), and an overnight preculture was inoculated to $1 \%$ in $500 \mathrm{ml}$ tryptone yeast extract (TYG) containing $50 \mu \mathrm{g} / \mathrm{ml}$ kanamycin, followed by incubation of the fresh culture for $16 \mathrm{~h}$ at $25^{\circ} \mathrm{C}$. Protein overexpression was induced by adding isopropyl $\beta$-D-thiogalactopyranoside (IPTG) to a final concentration of $200 \mu \mathrm{M}$. Recombinant protein production continued overnight at $25^{\circ} \mathrm{C}$, after which the cells were collected by centrifugation. FpCE17, FpCE2, FpGH113, and FpMOBP were purified by immobilized metal ion affinity chromatography (IMAC). To this aim, the harvested cell pellet was resuspended in binding buffer $(20 \mathrm{mM}$ sodium phosphate [pH 7.4], $500 \mathrm{mM}$ sodium chloride, $5 \mathrm{mM}$ imidazole) and lysed using a Vibracell ultrasonic homogenizer (Sonics and Materials, USA). The cell debris was pelleted by centrifugation, and the supernatant was loaded onto a 5-ml HisTrap IMAC HP nickel Sepharose column (GE Healthcare), using an ÄKTA Pure chromatography system (GE Healthcare). The target His-tagged protein was eluted using a linear gradient of 0 to $100 \%$ elution buffer ( $20 \mathrm{mM}$ sodium phosphate [pH 7.4], $500 \mathrm{mM}$ sodium chloride, $500 \mathrm{mM}$ imidazole) over 16 column volumes. FpGH36 was purified by hydrophobic interaction chromatography (HIC). FpGH36-containing cell pellet was resuspended in a buffer with $1.5 \mathrm{M}$ ammonium sulfate and lysed as described above. The cell-free supernatant was loaded onto a 5-ml HiTrap Phenyl FF (GE Healthcare), and protein was eluted by using a linear reverse gradient to $100 \mathrm{mM} \mathrm{NaCl}$ over $90 \mathrm{~min}$ at a flow rate of $2.5 \mathrm{ml} / \mathrm{min}$. After IMAC or HIC purification, eluted protein fractions were pooled, concentrated using a Vivaspin 20 centrifugal concentrator (10-kDa molecular weight cutoff), and applied to a HiLoad 16/600 Superdex $75 \mathrm{pg}$ gel filtration column (GE Healthcare). Pure protein samples were dialyzed against $10 \mathrm{mM} \mathrm{Tris- \textrm {HCl }}$ ( $\mathrm{pH} 7.0)$ and concentrated as described above. Protein purity was determined by sodium dodecyl sulfate-polyacrylamide gel electrophoresis (SDS-PAGE) analysis. Protein concentrations were determined using the Bradford assay (Bio-Rad, Germany).

Activity assays. Unless otherwise stated, enzyme reaction mixtures contained $10 \mathrm{mM}$ sodium phosphate $(\mathrm{pH} 5.8)$ and $0.1 \mathrm{mg} / \mathrm{ml}$ substrate. Reaction mixtures were preheated $\left(37^{\circ} \mathrm{C}\right.$ for $10 \mathrm{~min}$ ) in a Thermomixer $\mathrm{C}$ incubator with a heated lid (Eppendorf), before addition of the enzyme to $1 \mu \mathrm{M}$ (in a final reaction mixture volume of $100 \mu \mathrm{l}$ ) for further incubation (up to $16 \mathrm{~h}$ ) at $37^{\circ} \mathrm{C}$ and $700 \mathrm{rpm}$. All experiments were performed in triplicate.

MALDI-ToF MS analysis of oligosaccharides. Mannooligosaccharide products were analyzed by matrix-assisted laser desorption ionization-time of flight mass spectrometry (MALDI-ToF MS) on a Ultraflex MALDI-ToF/ToF MS instrument (Bruker Daltonics, Germany) equipped with a 337-nm-wavelength nitrogen laser and operated by the MALDI FlexControl software (Bruker Daltonics). A matrix of 2,5-dihydroxybenzoic acid (DHB) (0.9\% 2,5-dihydroxybenzoic acid-30\% acetonitrile [vol/vol]) was used. All measurements were performed in positive ion, reflector mode with 1,000 shots taken per spectrum.

Carbohydrate analysis using high-performance anion-exchange chromatography. Oligo- and monosaccharides were analyzed by high-performance anion-exchange chromatography with pulsed amperometric detection (HPAEC-PAD) on a Dionex ICS-3000 system operated by Chromeleon software 
version 7 (Dionex). Sugars were loaded onto a CarboPac PA1 $2 \times 250-\mathrm{mm}$ analytical column (Dionex, Thermo Scientific) coupled to a CarboPac PA1 $2 \times 50-\mathrm{mm}$ guard column kept at $30^{\circ} \mathrm{C}$. Depending on the analytes, the following gradients were used. The system was run at a flow rate of $0.25 \mathrm{ml} / \mathrm{min}$. For manno-oligosaccharides, the elution conditions were as follows: for 0 to $9 \mathrm{~min}, 0.1 \mathrm{M} \mathrm{NaOH}$; for 9 to $35 \mathrm{~min}, 0.1 \mathrm{M} \mathrm{NaOH}$ with a 0.1 to $0.3 \mathrm{M}$ sodium acetate ( $\mathrm{NaOAc}$ ) gradient; for 35 to $40 \mathrm{~min}, 0.1 \mathrm{M} \mathrm{NaOH}$ with $0.3 \mathrm{M} \mathrm{NaOAc}$, and for 40 to $50 \mathrm{~min} 0.1 \mathrm{M} \mathrm{NaOH}$. Commercial mannose and manno-oligosaccharides (DP, 2 to 6) were used as external standards.

Acetate release measurements using high-performance liquid chromatography. Acetate content in the samples was analyzed on an RSLC Ultimate 3000 (Dionex, USA) high-performance liquid chromatograph (HPLC) using a REZEX ROA-Organic Acid $\mathrm{H}+300 \times 7.8-\mathrm{mm}$ ion exclusion column (Phenomenex, USA). The injection volume was $5 \mu l$, and separation was conducted at $65^{\circ} \mathrm{C}$, with isocratic elution using $0.6 \mathrm{ml} / \mathrm{min}$ of $5 \mathrm{mM} \mathrm{H}_{2} \mathrm{SO}_{4}$ as the mobile phase. The UV detector was set at $210 \mathrm{~nm}$. Data collection and analysis were carried out with the Chromeleon 7.0 software (Dionex).

SCFA analysis. SCFA concentrations were measured using a gas chromatograph analyzer equipped with a flame ionization detector (GC-FID) as described previously (47). Following derivatization of the samples using $\mathrm{N}$-tertbutyldimethylsilyl- $\mathrm{N}$-methyltrifluoroacetamide, the samples were analyzed on a Hewlett-Packard 6890 gas chromatograph equipped with a silica capillary column using helium as the carrier gas. Quantification of SCFA in the chromatograms was determined based on the retention times of the respective SCFA standards (Sigma-Aldrich, United Kingdom) at concentrations ranging between 5 and $30 \mathrm{mM}$.

Isothermal titration calorimetry. Binding of mannohexaose and cellohexaose to FpMOBP was measured at $25^{\circ} \mathrm{C}$ in $50 \mathrm{mM}$ sodium phosphate $(\mathrm{pH}$ 6.5) using either a MicroCal ITC 200 microcalorimeter or a MicroCal VP-ITC system. To assess the binding to mannohexaose using a MicroCal ITC 200 microcalorimeter, FpMOBP in the sample cell $(2.5 \mu \mathrm{M})$ was titrated by a first injection of $0.5 \mu \mathrm{l}$ followed by $192-\mu \mathrm{l}$ injections of carbohydrate ligand $(2.5 \mathrm{mM})$ with $120 \mathrm{~s}$ between injections. To evaluate the binding to cellohexaose using a MicroCal VP-ITC system, FpMOBP in the sample cell $(22.5 \mu \mathrm{M})$ was titrated by a first injection of $2 \mu \mathrm{l}$ followed by $296-\mu \mathrm{l}$ injections of carbohydrate ligand $(2.5 \mathrm{mM})$ with $180 \mathrm{~s}$ between injections. Thermodynamic binding parameters were determined using either the MicroCal Origin software (version 7.0) or the VPviewer2000 software (version 2.6).

FpCE2 and FpCE17 optimal pH. The pH optima for FpCE17 and FpCE2 were assessed by incubation of the enzymes with $0.5 \mathrm{mM}$ 4-nitrophenyl (pNP) acetate (Sigma-Aldrich, Germany) at $25^{\circ} \mathrm{C}$ using $50 \mathrm{mM}$ sodium phosphate buffer at $\mathrm{pHs}$ ranging from 5.0 to 8.0. Due to the difference in deacetylation rate of pNP acetate by the two enzymes, $1 \mathrm{nM} \mathrm{FpCE2}$ and $0.1 \mu \mathrm{M} F p C E 17$ were used in these experiments. Standard plots of 4-nitrophenol ( $p$-nitrophenol; Sigma-Aldrich) were prepared at each $\mathrm{pH}$. The experiments were conducted in triplicate in a volume of $100 \mu \mathrm{l}$ of sample mixture in 96-well microtiter plates. The reaction was followed by measuring the absorbance at $405 \mathrm{~nm}$ at 1-min intervals for 10 min using a Microplate reader (BioTek, USA).

Protein thermal shift assay. The thermal stability of $F p C E 17$ and $F p C E 2$ was examined using the Protein Thermal Shift kit (ThermoFisher, USA) by measuring fluorescence in a real-time PCR system (Applied Biosystems, USA). A final concentration of $0.1 \mathrm{mg} / \mathrm{ml}$ of $F p C E 17$ and $F p C E 2$ was used in $50 \mathrm{mM}$ sodium phosphate buffers at $\mathrm{pH} 5.0$ to 8.0 and mixed with ROX dye according to the kit protocol. The melting temperature was executed in four replicates with temperatures from 25 to $99^{\circ} \mathrm{C}$ in $1 \%$ increments. The data were processed using the StepOne software (Applied Biosystems, USA).

Transesterification reactions. Transesterification of oligosaccharides was conducted using vinyl acetate (Thermo Scientific, USA) as acetate donors. Enzymes ( $1 \mu \mathrm{g} / \mathrm{ml}$ final concentration) were mixed with $1 \mathrm{mg} / \mathrm{ml}$ oligosaccharides, and a volume of vinyl acetate corresponding to $50 \%$ of the sample volume was added. The samples were incubated in a thermomixer (Eppendorf, Norway), shaking at $600 \mathrm{rpm}$, at ambient temperature overnight, then kept at $-20^{\circ} \mathrm{C}$ until frozen. The vinyl acetate, which remained in liquid phase on top of the frozen aqueous phase, was discarded; enzyme deactivation and carbohydrate precipitation were achieved by adjusting the aqueous phase to $80 \%$ (vol/vol) ethanol with ice-cold $96 \%$ ethanol. Enzymes were removed through filtration using a 1-ml Amicon Ultracel 3-kDa ultrafiltration device (Merck KGaA, Germany). The samples were then dried using an Eppendorf Concentrator plus

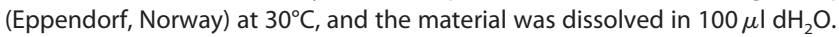

Comparative genomics analysis. Searches for the presence of MULL and MULS in other publicly available $F$. prausnitzii genomes were conducted using a similar strategy as described previously (7). Briefly, the identification of similar MULs in strains other than F. prausnitzii SL3/3 was done using BLASTN and the Gene Ortholog Neighborhood viewer on the Integrated Microbial Genomes website (https://img.jgi.doe.gov) using the sequences of the genes coding for FpMOBP (FPR_17280), FpGH113 (FPR_17310), and FpGH3 (FPR_09740) as the search homolog and the default threshold E value of 1e-5. If this generated a hit, we repeated the process with the adjacent gene to verify that the locus was found in the identified strain. Then, the amino acid identities between each F. prausnitzii SL3/3 MULL-MULS RefSeq annotated protein and the hits identified in other $F$. prausnitzii strains were determined by BLASTP-based analyses. Finally, we compared the genomic regions surrounding each orthologous MUL for gene conservation and amino acid identities.

Analysis of human gut metagenomic data sets for the presence of MULs. Available cohorts of human gut metagenomic sequence data (National Center for Biotechnology Information projects: PRJNA422434 (48), PRJEB10878 (49), PRJEB12123 (50), PRJEB12124 (51), PRJEB15371 (52), PRJEB6997 (53), PRJDB3601 (54), PRJNA48479 (20), PRJEB4336 (55), PRJEB2054 (56), PRJNA392180 (57), and PRJNA527208 (58) were searched for the presence of MUL nucleotide sequences from $F$. prauznitzii MULL (17.5 kb) and F. prauznitzii MULS (5.5 kb) using the following workflow. Each MUL nucleotide 
sequence was used separately as a template, and then Magic-BLAST (59) v1.5.0 was used to recruit raw Illumina reads from the available metagenomic data sets with an identity cutoff of $97 \%$. Next, the alignment files were used to generate a coverage map using bedtools (60) v2.29.0 to calculate the percentage coverage of each sample against each individual reference. We considered a metagenomic data sample to be positive for a particular MUL if it had at least $70 \%$ of the corresponding MUL nucleotide sequence covered.

Data availability. All data supporting the findings of this study are available within the article and supplemental material.

\section{SUPPLEMENTAL MATERIAL}

Supplemental material is available online only.

FIG S1, DOCX file, $0.1 \mathrm{MB}$.

FIG S2, DOCX file, $0.4 \mathrm{MB}$.

FIG S3, DOCX file, $0.1 \mathrm{MB}$.

TABLE S1, DOCX file, $0.03 \mathrm{MB}$.

TABLE S2, DOCX file, $0.04 \mathrm{MB}$.

\section{ACKNOWLEDGMENTS}

We are grateful for support from The Research Council of Norway (FRIPRO program to P.B.P.: 250479; BION/ER program to B.W.: 244259), the European Research Commission Starting Grant Fellowship (awarded to P.B.P.; 336355 MicroDE), and the Scottish Government Rural and Environmental Sciences and Analytical Services (RESAS) (for P.L. and S.H.D.).

S.L.L.R. generated constructs and performed recombinant protein production and purification and functional characterizations of the binding protein and GHs. L.J.L., S.L., and L.M. expressed, purified, and performed functional characterization of FpCE2 and FpCE17. Growth experiments on mannans and SCFA quantifications were performed by G.L. ITC was performed by Å.K.R., Z.L., and L.S.M. G.V.P. and S.L.L.R. conducted the human metagenomic analysis. S.L.L.R., P.B.P., and B.W. conceived the study and supervised research. The manuscript was written primarily by S.L.L.R. with contributions from P.B.P., S.H.D., G.L, L.M., S.L., G.V.P., E.C.M., L.S.M., B.W., and L.J.L. Figures were prepared by S.L.L.R.

We declare that we have no competing interests.

\section{REFERENCES}

1. El Kaoutari A, Armougom F, Gordon Jl, Raoult D, Henrissat B. 2013. The abundance and variety of carbohydrate-active enzymes in the human gut microbiota. Nat Rev Microbiol 11:497-504. https://doi.org/10.1038/nrmicro3050.

2. Louis P, Hold GL, Flint HJ. 2014. The gut microbiota, bacterial metabolites and colorectal cancer. Nat Rev Microbiol 12:661-672. https://doi.org/10 .1038/nrmicro3344.

3. Koropatkin NM, Cameron EA, Martens EC. 2012. How glycan metabolism shapes the human gut microbiota. Nat Rev Microbiol 10:323-335. https:// doi.org/10.1038/nrmicro2746.

4. Flint HJ, Scott KP, Duncan SH, Louis P, Forano E. 2012. Microbial degradation of complex carbohydrates in the gut. Gut Microbes 3:289-306. https://doi.org/10.4161/gmic.19897.

5. Cockburn DW, Koropatkin NM. 2016. Polysaccharide degradation by the intestinal microbiota and its influence on human health and disease. J Mol Biol 428:3230-3252. https://doi.org/10.1016/j.jmb.2016.06.021.

6. Martens EC, Koropatkin NM, Smith TJ, Gordon Jl. 2009. Complex glycan catabolism by the human gut microbiota: the Bacteroidetes Sus-like paradigm. J Biol Chem 284:24673-24677. https://doi.org/10.1074/jbc.R109.022848.

7. La Rosa SL, Leth ML, Michalak L, Hansen ME, Pudlo NA, Glowacki R, Pereira G, Workman CT, Arntzen MO, Pope PB, Martens EC, Hachem MA, Westereng B. 2019. The human gut Firmicute Roseburia intestinalis is a primary degrader of dietary beta-mannans. Nat Commun 10:905. https:// doi.org/10.1038/s41467-019-08812-y.

8. Leth ML, Ejby M, Workman C, Ewald DA, Pedersen SS, Sternberg C, Bahl MI, Licht TR, Aachmann FL, Westereng B, Abou Hachem M. 2018. Differential bacterial capture and transport preferences facilitate co-growth on dietary xylan in the human gut. Nat Microbiol 3:570-580. https://doi.org/10 .1038/s41564-018-0132-8.
9. Cockburn DW, Orlovsky NI, Foley MH, Kwiatkowski KJ, Bahr CM, Maynard M, Demeler B, Koropatkin NM. 2015. Molecular details of a starch utilization pathway in the human gut symbiont Eubacterium rectale. Mol Microbiol 95:209-230. https://doi.org/10.1111/mmi.12859.

10. Walker AW, Ince J, Duncan SH, Webster LM, Holtrop G, Ze X, Brown D, Stares MD, Scott P, Bergerat A, Louis P, Mclntosh F, Johnstone AM, Lobley GE, Parkhill J, Flint HJ. 2011. Dominant and diet-responsive groups of bacteria within the human colonic microbiota. ISME J 5:220-230. https://doi .org/10.1038/ismej.2010.118.

11. Balamurugan R, Rajendiran E, George S, Samuel GV, Ramakrishna BS. 2008. Real-time polymerase chain reaction quantification of specific butyrate-producing bacteria, Desulfovibrio and Enterococcus faecalis in the feces of patients with colorectal cancer. J Gastroenterol Hepatol 23:1298-1303. https://doi.org/10.1111/j.1440-1746.2008.05490.x.

12. Miquel S, Martin R, Rossi O, Bermudez-Humaran LG, Chatel JM, Sokol H, Thomas M, Wells JM, Langella P. 2013. Faecalibacterium prausnitzii and human intestinal health. Curr Opin Microbiol 16:255-261. https://doi.org/ 10.1016/j.mib.2013.06.003.

13. Lopez-Siles M, Martinez-Medina M, Suris-Valls R, Aldeguer X, Sabat-Mir M, Duncan SH, Flint HJ, Garcia-Gil LJ. 2016. Changes in the abundance of Faecalibacterium prausnitzii phylogroups I and II in the intestinal mucosa of inflammatory bowel disease and patients with colorectal cancer. Inflamm Bowel Dis 22:28-41. https://doi.org/10.1097/MIB.0000000000000590.

14. Sokol H, Pigneur B, Watterlot L, Lakhdari O, Bermudez-Humaran LG, Gratadoux JJ, Blugeon S, Bridonneau C, Furet JP, Corthier G, Grangette C, Vasquez N, Pochart P, Trugnan G, Thomas G, Blottiere HM, Dore J, Marteau P, Seksik P, Langella P. 2008. Faecalibacterium prausnitzii is an anti-inflammatory commensal bacterium identified by gut microbiota 
analysis of Crohn disease patients. Proc Natl Acad Sci U S A 105:1673116736. https://doi.org/10.1073/pnas.0804812105.

15. Martin R, Miquel S, Chain F, Natividad JM, Jury J, Lu J, Sokol H, Theodorou V, Bercik P, Verdu EF, Langella P, Bermudez-Humaran LG. 2015. Faecalibacterium prausnitzii prevents physiological damages in a chronic lowgrade inflammation murine model. BMC Microbiol 15:67. https://doi.org/ 10.1186/s12866-015-0400-1.

16. Wrzosek L, Miquel S, Noordine M-L, Bouet S, Chevalier-Curt M, Robert V, Philippe C, Bridonneau C, Cherbuy C, Robbe-Masselot C, Langella P, Thomas M. 2013. Bacteroides thetaiotaomicron and Faecalibacterium prausnitzii influence the production of mucus glycans and the development of goblet cells in the colonic epithelium of a gnotobiotic model rodent. BMC Biol 11:61. https://doi.org/10.1186/1741-7007-11-61.

17. Martin R, Miquel S, Benevides L, Bridonneau C, Robert V, Hudault S, Chain F, Berteau O, Azevedo V, Chatel JM, Sokol H, Bermudez-Humaran LG, Thomas M, Langella P. 2017. Functional characterization of novel Faecalibacterium prausnitzii strains isolated from healthy volunteers: a step forward in the use of $F$. prausnitzii as a next-generation probiotic. Front Microbiol 8:1226. https://doi.org/10.3389/fmicb.2017.01226.

18. Scheller HV, Ulvskov P. 2010. Hemicelluloses. Annu Rev Plant Biol 61:263-289. https://doi.org/10.1146/annurev-arplant-042809-112315.

19. Yamabhai M, Sak-Ubol S, Srila W, Haltrich D. 2016. Mannan biotechnology: from biofuels to health. Crit Rev Biotechnol 36:32-42. https://doi .org/10.3109/07388551.2014.923372.

20. Lloyd-Price J, Mahurkar A, Rahnavard G, Crabtree J, Orvis J, Hall AB, Brady A, Creasy HH, McCracken C, Giglio MG, McDonald D, Franzosa EA, Knight R, White O, Huttenhower C. 2017. Strains, functions and dynamics in the expanded Human Microbiome Project. Nature 550:61-66. https://doi.org/ 10.1038/nature23889.

21. Bagenholm V, Reddy SK, Bouraoui H, Morrill J, Kulcinskaja E, Bahr CM, Aurelius O, Rogers T, Xiao Y, Logan DT, Martens EC, Koropatkin NM, Stalbrand H. 2017. Galactomannan catabolism conferred by a polysaccharide utilization locus of Bacteroides ovatus: enzyme synergy and crystal structure of a beta-mannanase. J Biol Chem 292:229-243. https://doi.org/ 10.1074/jbc.M116.746438.

22. Senoura T, Ito S, Taguchi H, Higa M, Hamada S, Matsui H, Ozawa T, Jin S, Watanabe J, Wasaki J, Ito S. 2011. New microbial mannan catabolic pathway that involves a novel mannosylglucose phosphorylase. Biochem Biophys Res Commun 408:701-706. https://doi.org/10.1016/j.bbrc.2011.04 .095 .

23. Lopez-Siles M, Khan TM, Duncan SH, Harmsen HJ, Garcia-Gil LJ, Flint HJ. 2012. Cultured representatives of two major phylogroups of human colonic Faecalibacterium prausnitzii can utilize pectin, uronic acids, and hostderived substrates for growth. Appl Environ Microbiol 78:420-428. https://doi.org/10.1128/AEM.06858-11.

24. La Rosa SL, Kachrimanidou V, Buffetto F, Pope PB, Pudlo NA, Martens EC, Rastall RA, Gibson GR, Westereng B. 2019. Wood-derived dietary fibers promote beneficial human gut microbiota. mSphere 4:e00554-18. https:// doi.org/10.1128/mSphere.00554-18.

25. Schnorr SL, Candela M, Rampelli S, Centanni M, Consolandi C, Basaglia G, Turroni S, Biagi E, Peano C, Severgnini M, Fiori J, Gotti R, De Bellis G, Luiselli D, Brigidi P, Mabulla A, Marlowe F, Henry AG, Crittenden AN. 2014. Gut microbiome of the Hadza hunter-gatherers. Nat Commun 5:3654. https://doi.org/10.1038/ncomms4654.

26. You X, Qin Z, Yan Q, Yang S, Li Y, Jiang Z. 2018. Structural insights into the catalytic mechanism of a novel glycoside hydrolase family 113 beta-1,4mannanase from Amphibacillus xylanus. J Biol Chem 293:11746-11757. https://doi.org/10.1074/jbc.RA118.002363.

27. Merceron R, Foucault M, Haser R, Mattes R, Watzlawick H, Gouet P. 2012. The molecular mechanism of thermostable alpha-galactosidases AgaA and $\mathrm{AgaB}$ explained by $\mathrm{x}$-ray crystallography and mutational studies. J Biol Chem 287:39642-39652. https://doi.org/10.1074/jbc.M112.394114.

28. Michalak L, La Rosa SL, Leivers S, Lindstad LJ, Rohr AK, Lillelund Aachmann F, Westereng B. 2020. A pair of esterases from a commensal gut bacterium remove acetylations from all positions on complex betamannans. Proc Natl Acad Sci U S A 117:7122-7130. https://doi.org/10 .1073/pnas.1915376117.

29. van Dyk JS, Pletschke BI. 2013. Enzyme synergy for enhanced degradation of lignocellulosic waste, p 57-65. In Shukla P, Pletschke IB (ed), Advances in enzyme biotechnology. Springer, New Delhi, India.

30. Strucksberg KH, Rosenkranz T, Fitter J. 2007. Reversible and irreversible unfolding of multi-domain proteins. Biochim Biophys Acta 1774:1591-1603. https://doi.org/10.1016/j.bbapap.2007.09.005.
31. Bagenholm V, Wiemann M, Reddy SK, Bhattacharya A, Rosengren A, Logan DT, Stalbrand H. 2019. A surface-exposed GH26 beta-mannanase from Bacteroides ovatus: structure, role, and phylogenetic analysis of BoMan26B. J Biol Chem 294:9100-9117. https://doi.org/10.1074/jbc .RA118.007171.

32. Kawahara R, Saburi W, Odaka R, Taguchi H, Ito S, Mori H, Matsui H. 2012. Metabolic mechanism of mannan in a ruminal bacterium, Ruminococcus albus, involving two mannoside phosphorylases and cellobiose 2-epimerase: discovery of a new carbohydrate phosphorylase, beta-1,4-mannooligosaccharide phosphorylase. J Biol Chem 287:42389-42399. https://doi .org/10.1074/jbc.M112.390336.

33. Anand S, Kaur H, Mande SS. 2016. Comparative in silico analysis of butyrate production pathways in gut commensals and pathogens. Front Microbiol 7:1945. https://doi.org/10.3389/fmicb.2016.01945.

34. Hehemann JH, Correc G, Barbeyron T, Helbert W, Czjzek M, Michel G. 2010. Transfer of carbohydrate-active enzymes from marine bacteria to Japanese gut microbiota. Nature 464:908-912. https://doi.org/10.1038/ nature08937.

35. Ejby M, Guskov A, Pichler MJ, Zanten GC, Schoof E, Saburi W, Slotboom DJ, Abou Hachem M. 2019. Two binding proteins of the $A B C$ transporter that confers growth of Bifidobacterium animalis subsp. lactis ATCC27673 on beta-mannan possess distinct manno-oligosaccharide-binding profiles. Mol Microbiol 112:114-130. https://doi.org/10.1111/mmi.14257.

36. Larsbrink J, Rogers TE, Hemsworth GR, McKee LS, Tauzin AS, Spadiut O, Klinter S, Pudlo NA, Urs K, Koropatkin NM, Creagh AL, Haynes CA, Kelly AG, Cederholm SN, Davies GJ, Martens EC, Brumer H. 2014. A discrete genetic locus confers xyloglucan metabolism in select human gut Bacteroidetes. Nature 506:498-502. https://doi.org/10.1038/nature12907.

37. Tamura K, Hemsworth GR, Dejean G, Rogers TE, Pudlo NA, Urs K, Jain N, Davies GJ, Martens EC, Brumer H. 2017. Molecular mechanism by which prominent human gut Bacteroidetes utilize mixed-linkage beta-glucans, major health-promoting cereal polysaccharides. Cell Rep 21:417-430. https://doi.org/10.1016/j.celrep.2017.09.049.

38. Dejean G, Tamura K, Cabrera A, Jain N, Pudlo NA, Pereira G, Viborg AH, Van Petegem F, Martens EC, Brumer H. 2020. Synergy between cell surface glycosidases and glycan-binding proteins dictates the utilization of specific beta(1,3)-glucans by human gut Bacteroides. mBio 11:e00095-20. https://doi.org/10.1128/mBio.00095-20.

39. Cuskin F, Lowe EC, Temple MJ, Zhu Y, Cameron EA, Pudlo NA, Porter NT, Urs K, Thompson AJ, Cartmell A, Rogowski A, Hamilton BS, Chen R, Tolbert TJ, Piens K, Bracke D, Vervecken W, Hakki Z, Speciale G, Munōz-Munōz JL, Day A, Peña MJ, McLean R, Suits MD, Boraston AB, Atherly T, Ziemer CJ, Williams SJ, Davies GJ, Abbott DW, Martens EC, Gilbert HJ. 2015. Human gut Bacteroidetes can utilize yeast mannan through a selfish mechanism. Nature 517:165-169. https://doi.org/10.1038/nature13995.

40. Michalak L, Gaby JC, Lagos L, La Rosa SL, Hvidsten TR, Tetard-Jones C, Willats WGT, Terrapon N, Lombard V, Henrissat B, Droge J, Arntzen MO, Hagen LH, Overland M, Pope PB, Westereng B. 2020. Microbiota-directed fibre activates both targeted and secondary metabolic shifts in the distal gut. Nat Commun 11:5773. https://doi.org/10.1038/s41467-020-19585-0.

41. Miyazaki K, Martin JC, Marinsek-Logar R, Flint HJ. 1997. Degradation and utilization of xylans by the rumen anaerobe Prevotella bryantii (formerly P. ruminicola subsp. brevis) $\mathrm{B}(1) 4$. Anaerobe 3:373-381. https://doi.org/10 .1006/anae.1997.0125.

42. Wegmann U, Goesmann A, Carding SR. 2016. Complete genome sequence of Bacteroides ovatus V975. Genome Announc 4:e01335-16. https://doi.org/10.1128/genomeA.01335-16.

43. Duncan SH, Hold GL, Barcenilla A, Stewart CS, Flint HJ. 2002. Roseburia intestinalis sp. nov., a novel saccharolytic, butyrate-producing bacterium from human faeces. Int J Syst Evol Microbiol 52:1615-1620. https://doi .org/10.1099/00207713-52-5-1615.

44. Chung WSF, Meijerink M, Zeuner B, Holck J, Louis P, Meyer AS, Wells JM, Flint HJ, Duncan SH. 2017. Prebiotic potential of pectin and pectic oligosaccharides to promote anti-inflammatory commensal bacteria in the human colon. FEMS Microbiol Ecol https://doi.org/10.1093/femsec/fix127.

45. Petersen TN, Brunak S, von Heijne G, Nielsen H. 2011. SignalP 4.0: discriminating signal peptides from transmembrane regions. Nat Methods 8:785-786. https://doi.org/10.1038/nmeth.1701.

46. Aslanidis C, de Jong PJ. 1990. Ligation-independent cloning of PCR products (LIC-PCR). Nucleic Acids Res 18:6069-6074. https://doi.org/10.1093/ nar/18.20.6069.

47. Richardson A, Calder AG, Stewart CS, Smith A. 1989. Simultaneous determination of volatile and non-volatile acidic fermentation products of 
anaerobes by capillary gas chromatography. Lett Appl Microbiol 9:5-8. https://doi.org/10.1111/j.1472-765X.1989.tb00278.x.

48. Qin J, Li Y, Cai Z, Li S, Zhu J, Zhang F, Liang S, Zhang W, Guan Y, Shen D, Peng Y, Zhang D, Jie Z, Wu W, Qin Y, Xue W, Li J, Han L, Lu D, Wu P, Dai Y, Sun X, Li Z, Tang A, Zhong S, Li X, Chen W, Xu R, Wang M, Feng Q, Gong M, Yu J, Zhang Y, Zhang M, Hansen T, Sanchez G, Raes J, Falony G, Okuda S, Almeida M, LeChatelier E, Renault P, Pons N, Batto J-M, Zhang Z, Chen $\mathrm{H}$, Yang R, Zheng W, Li S, Yang H, et al. 2012. A metagenome-wide association study of gut microbiota in type 2 diabetes. Nature 490:55-60. https://doi.org/10.1038/nature11450.

49. Yu J, Feng Q, Wong SH, Zhang D, Liang QY, Qin Y, Tang L, Zhao H, Stenvang J, Li Y, Wang X, Xu X, Chen N, Wu WK, Al-Aama J, Nielsen HJ, Kiilerich P, Jensen BA, Yau TO, Lan Z, Jia H, Li J, Xiao L, Lam TY, Ng SC, Cheng AS, Wong VW, Chan FK, Xu X, Yang H, Madsen L, Datz C, Tilg H, Wang J, Brunner N, Kristiansen K, Arumugam M, Sung JJ, Wang J. 2017. Metagenomic analysis of faecal microbiome as a tool towards targeted non-invasive biomarkers for colorectal cancer. Gut 66:70-78. https://doi org/10.1136/gutjnl-2015-309800.

50. Liu R, Hong J, Xu X, Feng Q, Zhang D, Gu Y, Shi J, Zhao S, Liu W, Wang X, Xia H, Liu Z, Cui B, Liang $P$, Xi L, Jin J, Ying X, Wang X, Zhao X, Li W, Jia $H$, Lan Z, Li F, Wang R, Sun Y, Yang M, Shen Y, Jie Z, Li J, Chen X, Zhong H, Xie H, Zhang Y, Gu W, Deng X, Shen B, Xu X, Yang H, Xu G, Bi Y, Lai S, Wang J, Qi L, Madsen L, Wang J, Ning G, Kristiansen K, Wang W. 2017. Gut microbiome and serum metabolome alterations in obesity and after weight-loss intervention. Nat Med 23:859-868. https://doi.org/10.1038/ $\mathrm{nm} .4358$.

51. Gu Y, Wang X, Li J, Zhang Y, Zhong H, Liu R, Zhang D, Feng Q, Xie X, Hong J, Ren H, Liu W, Ma J, Su Q, Zhang H, Yang J, Wang X, Zhao X, Gu W, Bi Y, Peng Y, Xu X, Xia H, Li F, Xu X, Yang H, Xu G, Madsen L, Kristiansen K, Ning G, Wang W. 2017. Analyses of gut microbiota and plasma bile acids enable stratification of patients for antidiabetic treatment. Nat Commun 8:1785. https://doi.org/10.1038/s41467-017-01682-2.

52. He Q, Gao Y, Jie Z, Yu X, Laursen JM, Xiao L, Li Y, Li L, Zhang F, Feng Q, Li X, Yu J, Liu C, Lan P, Yan T, Liu X, Xu X, Yang H, Wang J, Madsen L, Brix S, Wang J, Kristiansen K, Jia H. 2017. Two distinct metacommunities characterize the gut microbiota in Crohn's disease patients. Gigascience 6:1-11. https://doi.org/10.1093/gigascience/gix050.

53. Zhang X, Zhang D, Jia H, Feng Q, Wang D, Liang D, Wu X, Li J, Tang L, Li Y, Lan Z, Chen B, Li Y, Zhong H, Xie H, Jie Z, Chen W, Tang S, Xu X, Wang X, Cai X, Liu S, Xia Y, Li J, Qiao X, Al-Aama JY, Chen H, Wang L, Wu QJ, Zhang F, Zheng W, Li Y, Zhang M, Luo G, Xue W, Xiao L, Li J, Chen W, Xu X, Yin Y,
Yang H, Wang J, Kristiansen K, Liu L, Li T, Huang Q, Li Y, Wang J. 2015. The oral and gut microbiomes are perturbed in rheumatoid arthritis and partly normalized after treatment. Nat Med 21:895-905. https://doi.org/ 10.1038/nm.3914.

54. Nishijima S, Suda W, Oshima K, Kim SW, Hirose Y, Morita H, Hattori M. 2016. The gut microbiome of healthy Japanese and its microbial and functional uniqueness. DNA Res 23:125-133. https://doi.org/10.1093/ dnares/dsw002.

55. Le Chatelier E, Nielsen T, Qin J, Prifti E, Hildebrand F, Falony G, Almeida M, Arumugam M, Batto JM, Kennedy S, Leonard P, Li J, Burgdorf K, Grarup N, Jorgensen T, Brandslund I, Nielsen HB, Juncker AS, Bertalan M, Levenez F, Pons N, Rasmussen S, Sunagawa S, Tap J, Tims S, Zoetendal EG, Brunak S, Clement K, Dore J, Kleerebezem M, Kristiansen K, Renault P, SicheritzPonten T, de Vos WM, Zucker JD, Raes J, Hansen T, Meta HIT Consortium, Bork P, Wang J, Ehrlich SD, Pedersen O. 2013. Richness of human gut microbiome correlates with metabolic markers. Nature 500:541-546. https://doi.org/10.1038/nature12506.

56. Qin J, Li R, Raes J, Arumugam M, Burgdorf KS, Manichanh C, Nielsen T, Pons N, Levenez F, Yamada T, Mende DR, Li J, Xu J, Li S, Li D, Cao J, Wang $B$, Liang $\mathrm{H}$, Zheng $\mathrm{H}$, Xie $\mathrm{Y}$, Tap J, Lepage $\mathrm{P}$, Bertalan $\mathrm{M}$, Batto J-M, Hansen T, Le Paslier D, Linneberg A, Nielsen HB, Pelletier E, Renault P, SicheritzPonten T, Turner K, Zhu H, Yu C, Li S, Jian M, Zhou Y, Li Y, Zhang X, Li S, Qin N, Yang H, Wang J, Brunak S, Doré J, Guarner F, Kristiansen K, Pedersen O, Parkhill J, Weissenbach J, MetaHIT Consortium, et al. 2010. A human gut microbial gene catalogue established by metagenomic sequencing. Nature 464:59-65. https://doi.org/10.1038/nature08821.

57. Smits SA, Leach J, Sonnenburg ED, Gonzalez CG, Lichtman JS, Reid G, Knight R, Manjurano A, Changalucha J, Elias JE, Dominguez-Bello MG, Sonnenburg JL. 2017. Seasonal cycling in the gut microbiome of the Hadza hunter-gatherers of Tanzania. Science 357:802-806. https://doi .org/10.1126/science.aan4834.

58. Conteville LC, Oliveira-Ferreira J, Vicente ACP. 2019. Gut microbiome biomarkers and functional diversity within an Amazonian semi-nomadic hunter-gatherer group. Front Microbiol 10:1743. https://doi.org/10.3389/ fmicb.2019.01743.

59. Boratyn GM, Thierry-Mieg J, Thierry-Mieg D, Busby B, Madden TL. 2019. Magic-BLAST, an accurate RNA-seq aligner for long and short reads. BMC Bioinformatics 20:405. https://doi.org/10.1186/s12859-019-2996-x.

60. Quinlan AR, Hall IM. 2010. BEDTools: a flexible suite of utilities for comparing genomic features. Bioinformatics 26:841-842. https://doi.org/10 $.1093 /$ bioinformatics/btq033. 